\title{
Do liquidity constraints matter in explaining firm size and growth? Some evidence from the Italian manufacturing industry
}

\author{
Giorgio Fagiolo and Alessandra Luzzi
}

\begin{abstract}
The article investigates whether liquidity constraints affect firm size and growth dynamics of Italian manufacturing firms. Panel-data regressions and distribution analyses show that (i) liquidity constraints engender a negative effect on growth once one controls for size; (ii) smaller firms grow more after controlling for liquidity constraints; and (iii) the stronger liquidity constraints, the more size negatively affects firm growth. Furthermore, we find that financial constraints help in better explaining the relationship between firm growth and age, conditional on size. Finally, our data indicate that size distributions depart from log-normality, and growth rates are well approximated by Laplace densities.
\end{abstract}

\section{Introduction}

This article investigates whether liquidity constraints faced by business firms affect the dynamics of firm size and growth. Since the seminal work of Gibrat (1931), the "Law of Proportionate Effects" (LPE) has become the empirical benchmark for the study of the evolution of firm size over time. In one of its most widely accepted interpretations, the LPE states that the growth rate of any firm is independent of its size at the beginning of the period examined. ${ }^{1}$ In turn, the underlying "random walk" description of firm (logs of) size dynamics entailed by the LPE implies, under quite general assumptions, a skewed log-normal limit distribution for firm size. ${ }^{2}$

In the last decades, a rather large body of empirical literature has been trying to test the LPE "null hypothesis" and its further implications upon industrial

\footnotetext{
${ }^{1}$ The LPE, also known as Gibrat's Law (GL), can be stated in terms of expected values as well. As Sutton (1997) puts it, the "expected value of the increment firm's size in each period is proportional to the current size of the firm." See also Mansfield (1962).

${ }^{2}$ Notice that the LPE might also form the core of a simple, stochastic, model of firm dynamics. See, for example, Simon and Bonini (1958), Ijiri and Simon (1977), and Geroski (2000). For a more general discussion cf. Steindl (1965), Cabral (1995), Sutton (1997, 1998), and Mitzenmacher (2002).
} 
organization. ${ }^{3}$ Yet, the evidence provided by these contributions is rather mixed, if not contradicting. For example, panel data analyses suggest that LPE should only hold for large manufacturing firms. Moreover, there seem to be many indications supporting the idea that, when only surviving firms are considered, average growth rates-as well as their variance-are decreasing with both size and age. However, despite their statistical significance, estimated growth-size correlations appear to be rather weak, especially once sample selection biases are taken into account.

More recently, the robustness of the existing evidence in favor of (or rejecting) a LPE type of dynamics has been questioned by (at least) two streams of research. ${ }^{4}$ First, as noticed in Bottazzi and Secchi (2003b), investigations of firm growth and size dynamics are typically carried out using aggregated data (over different sectors). This might lead to the emergence of statistical regularities-as the LPEwhich could only be the result of aggregation of persistently heterogeneous firm dynamics.

Second, and more important to our discussion here, the traditional approach has stressed the investigation of growth-size relationships without extensively addressing a detailed analysis of other determinants of firm growth (Becchetti and Trovato, 2002). More specifically, the majority of contributions has focused on panel data regressions including as explanatory variables only size and age-related measures, as well as non-linear effects, time and industry dummies, and so on. Very little attention has been paid to other determinants of firm growth and size dynamics, such as financial factors.

In the last years, however, a growing number of contributions has provided robust empirical evidence showing that financial factors (e.g., liquidity constraints, availability of external finance, access to foreign markets, etc.) can have a significant impact on firms investment decisions. While traditional research on investment was based on the neoclassical theory of optimal capital accumulation (see the extensive survey by Jorgenson, 1971), more recent literature has increasingly incorporated the idea that asymmetric information in financial markets leads to credit rationing and that the latter-in turn-influences investment markets (Stiglitz and Weiss, 1981). The seminal study of Fazzari and Athey (1987) was the first attempt at linking theoretical work on asymmetric information and imperfections in the capital markets with empirical studies in the investment literature. Later, several authors have analyzed the relationship

\footnotetext{
${ }^{3}$ An exhaustive survey of the LPE literature is of course beyond the scope of this article. The interested reader may refer to Carroll and Hannan (1999), Geroski (2000), and Lotti et al. (2003) (and references therein) for quite complete overviews.

${ }^{4}$ The LPE can be violated not only because a statistically significant correlation between average growth and size is present, but also because (i) higher moments of the growth rates distribution (e.g., variance) show some size-dependence (Bottazzi et al., 2002); (ii) the (limit) size distribution departs from log-normality (Bottazzi et al., 2001); and (iii) growth rate distributions are not normally distributed (Bottazzi and Secchi, 2003a).
} 
between firm financial factors and investment decisions. ${ }^{5}$ Liquidity constraintsmostly measured by scaled measures of cash flow-have been shown to negatively affect firm's investment in Belgium, France, Germany, the United States, and Italy (Devereaux and Schiantarelli, 1989; Galeotti et al., 1994; Bond et al., 2003 among others) and to increase the likelihood of firm failure (Holtz-Eakin et al., 1994). Moreover, small and young firms seem to invest more, but their investment is highly sensible to liquidity constraints (Fazzari et al., 1988a; Gilchrist and Himmelberg, 1995).

If financial factors significantly impact on firms' investment decisions, then they are likely to affect firm size and growth dynamics as well. For instance, highly liquidityconstrained firms might face difficulties in financing their investments and thus suffer from lower growth rates in the future (Fazzari et al., 1988a; Devereaux and Schiantarelli, 1989). At the same time, size and age may affect the ability of the firm to weaken its liquidity constraints and to gain access to external financing. ${ }^{6}$ Notice that, while the causal relationship going from liquidity constraints to size-through investment and growth — should typically occur at a higher frequency, one expects size and age to affect liquidity constraints over a longer time scale. Larger and older firms might indeed face difficulties in financing their investment with internal sources-for example, because of low cash flow-but, at the same time, easily access to external financing because they belong to well-established socioeconomic networks built over the years.

In this article, we begin to explore whether the emergence of any LPE type of dynamics — or violations thereof — might be influenced by taking directly into account financial factors (i.e., liquidity constraints) in studying the patterns of firm size and growth. Following Elston (2002), we argue that controlling for liquidity constraints may help in discriminating between "financial-related" and "sheer" size effects. While the first type of size effect should account for higher growth rates due to better access to external capital and/or higher cash flow, the latter might explain higher growth rates in terms of economies of scale and scope only. Since existing contributions investigating the LPE did not introduce any controls for financial constraints, ${ }^{7}$ their estimates of the impact of firm size on future firm growth might have been the result of a composition of "sheer" and "financial-related" effects.

Furthermore, we analyze the effects of firm financial constraints on the relationship between age and growth, conditional on size. Indeed, some authors have recently

\footnotetext{
${ }^{5}$ Space constraints prevent us to discuss here this rather large literature. See, among others, Fazzari et al. (1988a,b); Hoshi et al. (1991); Hall (1992); Bond and Meghir (1994); Schiantarelli (1996); Fazzari et al. (1996); Kaplan and Zingales (1997); Hu and Schiantarelli (1997); Hubbard (1998); and Mairesse et al. (1999).

${ }^{6}$ Harhoff et al. (1998) find that limited-liability firms experience significantly higher growth than unlimited-liability ones. Moreover, Lang et al. (1996) provide evidence in favor of a negative correlation between leverage and future firms' growth.

${ }^{7}$ With the exceptions of Becchetti and Trovato (2002) and Elston (2002). Cf. also Carpenter and Petersen (2002).
} 
emphasized the role played by financial factors on size-age-growth dynamics. In particular, Cooley and Quadrini (2001) have shown (from a theoretical perspective) that firms' technological differences in presence of financial market frictions can account for the negative relationship between firm growth and age, once one controls for firm size. Notice that earlier models of industry dynamics, being mainly based on technology learning and persistent technological shocks, were only able to explain the unconditional dependence of firm growth dynamics on size and age (see for example Jovanovic, 1982; Hopenhayn, 1992). Along the same vein, Cabral and Mata (2003) analyze the evolution of the (log) size distribution for a given cohort of firms on a sample of Portuguese data. They find that the distribution is highly skewed to the right at birth, but it can be well approximated by a log-normal distribution as firm age increases, even after having taken into account selection pressure (e.g., entry and exit). Cabral and Mata (2003) argue that financial constraints tend to weaken over time so that firms are allowed to reach their optimal size. This, in turn, should give rise to a more symmetric size distribution.

We employ a database containing observations on 14,277 (surviving) Italian manufacturing firms from 1995 to 2000 . The sample was originated from the AIDA database, covering $90 \%$ of all Italian firms with sales larger than $1 \mathrm{M}$ Euros. We begin by performing standard (pooled) Gibrat's type regressions to assess the impact of liquidity constraints on employees growth rates. We employ cash flow scaled by firm sales $(S C F)$ as a proxy of liquidity constraints and we control for size and age, as well as their lagged values and fixed time and sectoral effects. ${ }^{8}$ We show that liquidity constraints engender a negative, statistically significant, effect on growth once one controls for sheer size. Moreover, younger and smaller firms grow more, even after controlling for liquidity constraints. However, both the goodness-of-fit and the magnitude of estimated coefficients appear to be very weak. ${ }^{9}$ Therefore, as suggested in Bottazzi et al. (2002), we move toward a more detailed exploration of the statistical properties of the joint distribution of firms' size and growth, conditioned on SCF and age.

First, we explore the properties of the joint, pooled, distribution of size, growth, and SCF. We find that size distributions depart from log-normality while growth rates are well approximated by fat-tailed, tent-shaped (Laplace) densities. Moreover, firms facing stronger liquidity constraints grow less and experience more volatile growth patterns. The stronger liquidity constraints, the larger the absolute value of the observed size-growth correlation. Growth rate distributions seem, however, to be quite robust to $S C F$, once one controls for mean-variance time-shifts in their distributions.

Second, we investigate the evolution over time of the distributions of size and growth, conditioning on liquidity constraints and/or age. Our exercises suggest that

\footnotetext{
${ }^{8}$ See Section 2 for a discussion of econometric and data-related issues involved in the exercises presented in the paper.

${ }^{9}$ Significant but very small growth-size correlations are typically the case in the majority of empirical studies which find a violation of the LPE, cf. Lotti et al. (2003).
} 
the absolute value of the size-growth correlation has substantially decreased through time for any level of SCF. In addition, liquidity constraints do not seem to engender a strongly negative impact on firm growth in any given year. Thus, the negative impact of liquidity constraints on firm growth, which was quite strong in our pooled sample, becomes ambiguous when one disaggregates over time.

Finally, in line with Cooley and Quadrini (2001), we empirically assess the link between financial constraints and age. We show that the presence of financial constraints contributes to explain the age effect on firm growth after controlling for size. Contrary to Cabral and Mata (2003), no evolution from rightly skewed to log-normal ( $\log$ ) size distribution is detectable in our data.

The article is organized as follows. In Section 2, we describe the database that we employ in our empirical analyses and we discuss some important measurement and data-related issues. Section 3 presents the results of standard regression analyses. The properties of (pooled) distributions are explored in Section 4. In Section 5, we study the evolution over time of size and growth distributions while the effects of age and size on firm growth dynamics are briefly examined in Section 6. Finally, Section 7 concludes.

\section{Data}

Our empirical analysis is based on firm-level observations from the AIDA database developed by Italian Chambers of Commerce and further elaborated by Bureau Van Dijk. ${ }^{10}$ The database contains longitudinal data from 1992 to 2000 about size, age, and financial variables obtained by the balance sheets of $90 \%$ of all Italian firms whose sales have exceeded $1 \mathrm{M}$ Euros for at least one year in the observed period. ${ }^{11}$ We begin by studying firms belonging to the manufacturing sector as a whole. ${ }^{12}$

In order to keep statistical consistency, we analyze data for the period 1995-2000. Furthermore, we focus on unconsolidated budgets so as to avoid effects on growth and size due to mergers and acquisitions that may have occurred during the observed period. Indeed, if one instead considers consolidated budgets, mergers and acquisitions of lines of business belonging to any parent firm may show up in the consolidated budget of the parent firm. ${ }^{13}$

\footnotetext{
${ }^{10}$ See http://www.bvdep.it/aida.htm for additional details.

${ }^{11} \mathrm{~A}$ company enters the database the year its sales exceed $1 \mathrm{M}$ Euros. Data for previous years are then recovered. Notice that no lower bounds for employees are in principle present.

${ }^{12}$ According to the ATECO 2 classification, we study all firms whose principal activity ranges from code 15 to code 37 . For the manufacturing sector, the ATECO 2 classification matches the ISIC one with some minor exceptions.

${ }^{13} \mathrm{An}$ alternative strategy allowing to wash-away mergers and acquisitions effects is to build "superfirms" (Bottazzi et al., 2001, 2002).
} 
Our balanced sample consists of $N=14,277$ observations (per year). We use annual data on employees $(E M P)$ as our main proxy for firm size. Alternative measures of firm size such as sales $(S A L)$ and value added $(V A)$ —computed as after tax net operating profits minus total cost of capital—are also considered in order to check the robustness of our results.

In line with existing literature, we employ cash flow, scaled by some measure of firm size, as our proxy for firms' liquidity constraints. More formally, we define the scaled cash flow variable (or "cash flow ratio"):

$$
S C F_{i, t}=\frac{C F_{i, t}}{S A L_{i, t}}
$$

where $i=1, \ldots, N$ are firms' labels, $t=1996, \ldots, 2000$, and $C F_{i, t}$ is calculated as net firm revenues plus total depreciation (credits depreciation included). ${ }^{14} \mathrm{We}$ also employ firm age $(A G E)$ at the beginning of 1995 (the year of firm's birth is directly available in the database). Growth rates for each size variable $X=E M P, S A L, V A$ are computed as

$$
X_{-} G R_{i, t}=\Delta \log \left(X_{i, t}\right)=\log \left(X_{i, t}\right)-\log \left(X_{i, t-1}\right) .
$$

As explained above, our goal is to study the extent to which liquidity constraints might affect firm size-age-growth dynamics. To do so, we focus on single equation models, as well as on statistical properties of joint distributions. Thus, we do not address here the investigation of structural models of firms' investment behavior and growth. Nonetheless, several data-related issues require a more detailed discussion.

First, cash flow ratios are used as a proxy of liquidity constraints. The rationale is that a low cash flow ratio (i.e., a small $S C F$ ) may imply, especially for small firms, strong liquidity constraints. In fact, firms holding a large cash flow ratio are more likely to be able to finance internally their investments (Fazzari et al., 1988b). Furthermore, in presence of imperfect capital markets, a high cash flow ratio might also function as a "screening device" to gain a better access to external financing. In presence of credit rationing, larger cash flow ratios might then be used to get additional external funding, especially when firms have some convenience to "go external" for

\footnotetext{
${ }^{14}$ Cf., for example, Kaplan and Zingales (1997), Fazzari et al. (1996), and Audretsch and Elston (2002). All subsequent results do not dramatically change if alternative specifications for the cashflow ratio-for example, $\log (C F) / \log (S A L)$ or $\log (C F / S A L)$ - are taken into account. We also repeated all regression exercises and distribution analyses employing alternative scaling variables (e.g., total assets, capital stock, etc.), and we did not observe any remarkable departure from our basic findings.
} 
tax reasons. ${ }^{15}$ Indeed, high cash flow firms can always choose the right mix between internal and external financing if they have this option (i.e., if the "signaling" effect is present). ${ }^{16}$

Second, as noticed by Becchetti and Trovato (2002) and Elston (2002), cash flow can be highly correlated with other size measures such as sales or value added. To minimize the consequences of this problem, we scale $C F$ with $S A L$ and we always use employees $(E M P)$ as our size measure whenever liquidity constraints enter the picture. In addition, we check the robustness of all exercises involving only size-related measures by using alternative size measures such as sales $(S A L)$ and value added (VA).

Third, we only observe "surviving" firms in our sample. This can generate a survival bias, as high-growth (small) firms may be over-represented in our data (Lotti et al., 2003). Unfortunately, we do not have any direct empirical evidence which might allow us to distinguish between missing values and entry-exit events. Hence, we performed a preliminary descriptive analysis on size-growth distributions of firms that were excluded from our database because some missing values did appear in their records. We did not find any statistically significant distribution difference between "included" firms and "excluded" ones. Therefore, we argue that survival biases should not dramatically affect the results that follow.

Fourth, firms in our database are defined in terms of "lines of business" that can possibly belong to groups consisting of a parent firm and different subsidiaries. In all these cases (3.4\% of all observations), the cash flow ratio of a controlled firm might not be a good proxy for its actual liquidity constraints, as each line of business may have access to credit in proportion to cash flow ratios of the parent firm. In order to control for this, we considered information about parental affiliation. More specifically, we defined in our regression analysis the dummy variable $D_{\text {subs }}$, which is equal to one if the share of a firm's ownership held by shareholders is greater than $50 \%$ at the end of each year. On the contrary, as far as distribution analyses are concerned, we simply dropped these observations from our sample (this procedure did not change our results in any substantial way).

Table 1 reports summary statistics for firm size (EMP, VA, SAL) and their growth rates (EMP_GR, VA_GR, SAL_GR), liquidity constraints $(S C F)$ and age (AGE). All size distributions, as well as scaled cash flow distribution, are extremely skewed to the right as expected while growth rates appear to be almost symmetric and quite concentrated around their average values.

\footnotetext{
${ }^{15}$ See, however, Galeotti et al. (1994), Goyal et al. (2002), and Albuquerque and Hopenhayn (forthcoming) for alternative approaches employing debt-related variables as measures of liquidity constraints.

${ }^{16}$ Furthermore, cash flow is a relatively "fast" variable which can better account for the short-term impact of liquidity constraints on investments and growth. Since we expect the feedback from sizeage to liquidity constraints to be slower (especially for smaller, young, firms) and we only have data about six years, scaled cash flow has in our opinion an additional justification from a "dynamic" perspective.
} 
Table 1 Summary statistics for non-standardized data

\begin{tabular}{|c|c|c|c|c|c|c|c|}
\hline Variable & Year & Mean & SD & $\begin{array}{l}\text { Variation } \\
\text { Coefficient }\end{array}$ & Median & Kurtosis & Skewness \\
\hline & 1995 & 96.01 & 1026.27 & 10.69 & 35.00 & 6897.89 & 77.36 \\
\hline & 1996 & 98.60 & 705.22 & 7.15 & 38.00 & 6459.91 & 70.60 \\
\hline \multirow[t]{6}{*}{$E M P$} & 1997 & 100.95 & 683.15 & 6.77 & 40.00 & 5707.06 & 65.36 \\
\hline & 1998 & 101.30 & 650.69 & 6.42 & 40.00 & 5280.79 & 62.37 \\
\hline & 1999 & 100.14 & 572.44 & 5.72 & 40.00 & 4439.05 & 55.80 \\
\hline & 2000 & 101.58 & 400.63 & 3.94 & 41.00 & 806.09 & 23.67 \\
\hline & 1995 & $20,145.52$ & $19,4548.99$ & 9.66 & 6669.00 & 8153.74 & 81.48 \\
\hline & 1996 & $20,224.12$ & $16,0180.08$ & 7.92 & 6800.00 & 6155.25 & 67.89 \\
\hline \multirow[t]{6}{*}{$S A L$} & 1997 & $22,420.34$ & $19,6892.42$ & 8.78 & 7123.00 & 5611.88 & 64.68 \\
\hline & 1998 & $22,856.39$ & $18,6945.17$ & 8.18 & 7477.00 & 5721.81 & 65.10 \\
\hline & 1999 & $23,719.82$ & $19,3310.99$ & 8.15 & 7516.00 & 5579.45 & 63.93 \\
\hline & 2000 & $25,707.81$ & $15,5260.23$ & 6.04 & 8245.00 & 1107.74 & 28.96 \\
\hline & 1995 & 5055.55 & $45,556.89$ & 9.01 & 1676.00 & 7162.51 & 75.72 \\
\hline & 1996 & 4978.80 & $28,630.23$ & 5.75 & 1739.00 & 2393.64 & 40.68 \\
\hline \multirow[t]{6}{*}{ VA } & 1997 & 5479.97 & $40,985.14$ & 7.48 & 1776.00 & 3592.83 & 52.64 \\
\hline & 1998 & 5527.24 & $33,573.26$ & 6.07 & 1840.00 & 1887.94 & 37.58 \\
\hline & 1999 & 5658.97 & $32,799.82$ & 5.80 & 1895.00 & 2031.77 & 38.27 \\
\hline & 2000 & 6011.42 & $36,595.92$ & 6.09 & 1987.00 & 3682.48 & 49.43 \\
\hline & 1995 & 1397.81 & $17,971.56$ & 12.86 & 323.00 & 5076.67 & 63.38 \\
\hline & 1996 & 1222.26 & $12,462.08$ & 10.20 & 317.00 & 4182.24 & 52.82 \\
\hline \multirow[t]{6}{*}{$C F$} & 1997 & 1473.15 & $30,412.31$ & 20.64 & 316.00 & 8549.94 & 82.34 \\
\hline & 1998 & 1445.30 & $20,350.60$ & 14.08 & 324.00 & 9696.49 & 89.39 \\
\hline & 1999 & 1600.97 & $26,633.23$ & 16.64 & 348.00 & $10,924.46$ & 98.24 \\
\hline & 2000 & 2140.89 & $45,365.32$ & 21.19 & 353.00 & 7524.51 & 81.42 \\
\hline & 1995 & 0.07 & 0.33 & 4.57 & 0.05 & $10,603.81$ & 96.88 \\
\hline & 1996 & 0.07 & 0.42 & 6.19 & 0.05 & $12,628.96$ & 109.56 \\
\hline \multirow[t]{6}{*}{ CF/SAL } & 1997 & 0.06 & 0.13 & 2.05 & 0.05 & 5490.84 & 62.15 \\
\hline & 1998 & 0.06 & 0.08 & 1.33 & 0.05 & 3606.24 & 18.02 \\
\hline & 1999 & 0.07 & 0.08 & 1.21 & 0.05 & 4494.65 & 14.82 \\
\hline & 2000 & 0.05 & 0.43 & 9.09 & 0.04 & 2844.92 & 17.77 \\
\hline & 1996 & 0.12 & 0.30 & 0.41 & 0.09 & 84.90 & 3.15 \\
\hline & 1997 & 0.03 & 0.24 & 0.14 & 0.02 & 70.32 & 1.20 \\
\hline \multirow[t]{5}{*}{$E M P \_G R$} & 1998 & 0.00 & 0.29 & 0.01 & 0.00 & 56.54 & -3.39 \\
\hline & 1999 & -0.06 & 0.48 & -0.12 & 0.00 & 19.87 & -1.95 \\
\hline & 2000 & 0.04 & 0.68 & 0.05 & 0.04 & 13.89 & -1.07 \\
\hline & 1996 & 0.03 & 0.32 & 0.11 & 0.02 & 82.76 & 3.59 \\
\hline & 1997 & 0.04 & 0.26 & 0.17 & 0.04 & 122.06 & 4.08 \\
\hline
\end{tabular}


Table 1 Continued

\begin{tabular}{lccccccr}
\hline Variable & Year & Mean & SD & $\begin{array}{c}\text { Variation } \\
\text { Coefficient }\end{array}$ & Median & Kurtosis & Skewness \\
\hline SAL_GR & 1998 & 0.04 & 0.23 & 0.18 & 0.04 & 44.81 & 0.43 \\
& 1999 & 0.01 & 0.24 & 0.04 & 0.01 & 47.59 & 0.23 \\
& 2000 & 0.07 & 0.32 & 0.22 & 0.09 & 68.86 & -4.22 \\
& 1996 & 0.05 & 0.35 & 7.32 & 0.04 & 38.08 & 1.63 \\
& 1997 & 0.03 & 0.30 & 9.11 & 0.03 & 63.11 & 1.26 \\
\hline VA_GR & 1998 & 0.03 & 0.29 & 9.08 & 0.04 & 32.14 & -0.67 \\
& 1999 & 0.03 & 0.31 & 11.64 & 0.03 & 36.93 & 0.02 \\
& 2000 & 0.03 & 0.39 & 13.25 & 0.05 & 41.41 & -2.76 \\
\hline AGE & 1995 & 27.93 & 83.83 & 0.33 & 21.00 & 533.58 & 22.81 \\
\hline
\end{tabular}

$C F$, cash flow; $E M P$, employees; $G R$, growth rate; $N, 14,277$ firms observed; $S A L$, sales; $V A$, value added.

Correlation matrices for all key variables are reported in Tables 2 and 3. As expected, $C F$ is highly (positively) correlated with $V A$ both simultaneously and at oneyear lags while smaller but still relevant correlations emerge with $S A L$ and, in particular, with EMP. On the contrary, CF/SAL is weakly correlated with all size measures. This seems to be an additional justification for employing $S C F$ as our proxy for liquidity constraints and EMP as size-measure in our analysis.

Both average values and coefficients of variation present weak time-trends, suggesting some non-stationarity of size and SCF distributions. However, once one defines size and SCF variables in terms of their "normalized" values with respect to year-averages

$$
\tilde{X}_{i, t}=\frac{X_{i, t}}{N^{-1} \sum_{j=1}^{N} X_{j, t}},
$$

all distributions become stationary over time. Indeed, as Figure 1 shows for the log of standardized $E M P$ variable $(\widetilde{E M P})$, all first moments exhibit almost no variation over time.

Similar results hold for all other size measures and for SCF. Thus, all our pooled distribution analyses will be performed in terms of $\tilde{X}_{i, t}$ variables. ${ }^{17}$ As far as regression analyses are concerned, we will begin by employing non-standardized values and we

\footnotetext{
${ }^{17}$ For a more detailed discussion on this standardization procedure, see Kalecki (1945), Hart and Prais (1956), and Bottazzi et al. (2001).
} 
Table 2 Correlation structure

\begin{tabular}{|c|c|c|c|c|}
\hline & $S A L$ & $V A$ & $C F$ & CF/SAL \\
\hline \multicolumn{5}{|l|}{2000} \\
\hline$E M P$ & 0.7716 & 0.7270 & 0.4071 & 0.0152 \\
\hline$S A L$ & - & 0.7104 & 0.4905 & 0.0140 \\
\hline$V A$ & - & - & 0.8171 & 0.0314 \\
\hline$C F$ & - & - & - & 0.0444 \\
\hline \multicolumn{5}{|l|}{1999} \\
\hline$E M P$ & 0.8921 & 0.8418 & 0.2626 & 0.0333 \\
\hline$S A L$ & - & 0.7689 & 0.2716 & 0.0171 \\
\hline$V A$ & - & - & 0.6983 & 0.1025 \\
\hline$C F$ & - & - & - & 0.1488 \\
\hline \multicolumn{5}{|l|}{1998} \\
\hline$E M P$ & 0.9135 & 0.8503 & 0.2603 & 0.0328 \\
\hline$S A L$ & - & 0.8489 & 0.3968 & 0.0126 \\
\hline$V A$ & - & - & 0.6691 & 0.0490 \\
\hline$C F$ & - & - & - & 0.1457 \\
\hline \multicolumn{5}{|l|}{1997} \\
\hline$E M P$ & 0.8957 & 0.8848 & 0.3426 & 0.0211 \\
\hline$S A L$ & - & 0.9121 & 0.5444 & 0.0126 \\
\hline$V A$ & - & - & 0.7065 & 0.0381 \\
\hline$C F$ & - & - & - & 0.0689 \\
\hline \multicolumn{5}{|l|}{1996} \\
\hline$E M P$ & 0.9234 & 0.9316 & 0.3990 & 0.0153 \\
\hline$S A L$ & - & 0.8892 & 0.4541 & 0.0004 \\
\hline$V A$ & - & - & 0.4557 & -0.0120 \\
\hline$C F$ & - & - & - & 0.7136 \\
\hline \multicolumn{5}{|l|}{1995} \\
\hline$E M P$ & 0.8273 & 0.8455 & 0.7443 & 0.0122 \\
\hline$S A L$ & - & 0.9544 & 0.8524 & 0.0013 \\
\hline$V A$ & - & - & 0.8813 & -0.0066 \\
\hline $\mathrm{CF}$ & - & - & - & 0.3591 \\
\hline
\end{tabular}

$C F$, cash flow; EMP, employees; $S A L$, sales; $V A$, value added.

Contemporaneous distributions of size measures and cash flow.

will introduce year dummies to control for non-stationarity. We will also check the robustness of our results by using pooled distributions of standardized values $\tilde{X}_{i, t}$. In this case, growth rates are accordingly computed as $\tilde{X}_{-} G R_{i, t}=\Delta \log \left(\tilde{X}_{i, t}\right)$. Summary statistics and correlation structure for pooled, standardized distributions are reported in Tables 4 and 5. 
Table 3 One-year lagged correlations

\begin{tabular}{|c|c|c|c|c|c|}
\hline & $E M P$ & $S A L$ & $V A$ & $C F$ & $C F / S A L$ \\
\hline \multicolumn{6}{|c|}{ 2000-1999 } \\
\hline$E M P$ & - & 0.7340 & 0.8351 & 0.2934 & 0.0541 \\
\hline SAL & 0.7670 & - & 0.7825 & 0.3645 & 0.0360 \\
\hline VA & 0.6321 & 0.5748 & - & 0.8232 & 0.1238 \\
\hline$C F$ & 0.4778 & 0.4999 & 0.7727 & - & 0.1126 \\
\hline CF/SAL & 0.0126 & 0.0109 & 0.0290 & 0.0293 & - \\
\hline \multicolumn{6}{|c|}{ 1999-1998 } \\
\hline$E M P$ & - & 0.9092 & 0.8598 & 0.2747 & 0.0362 \\
\hline SAL & 0.8951 & - & 0.7669 & 0.2631 & 0.0638 \\
\hline$V A$ & 0.8304 & 0.8273 & - & 0.6897 & 0.0729 \\
\hline$C F$ & 0.2574 & 0.3767 & 0.6550 & - & 0.0798 \\
\hline CF/SAL & 0.0313 & 0.0298 & 0.0950 & 0.1350 & - \\
\hline \multicolumn{6}{|c|}{ 1998-1997 } \\
\hline$E M P$ & - & 0.8939 & 0.8889 & 0.3463 & 0.0214 \\
\hline SAL & 0.9120 & - & 0.9050 & 0.4993 & 0.0133 \\
\hline$V A$ & 0.8358 & 0.8373 & - & 0.6364 & 0.0437 \\
\hline$C F$ & 0.2476 & 0.4225 & 0.6441 & - & 0.0609 \\
\hline CF/SAL & 0.0344 & 0.0217 & 0.0544 & 0.0689 & - \\
\hline \multicolumn{6}{|c|}{ 1997-1996 } \\
\hline$E M P$ & - & 0.9190 & 0.9372 & 0.4610 & 0.0786 \\
\hline SAL & 0.8799 & - & 0.8315 & 0.6252 & 0.2490 \\
\hline$V A$ & 0.8453 & 0.8230 & - & 0.7791 & 0.4807 \\
\hline$C F$ & 0.2855 & 0.3202 & 0.2238 & - & 0.8524 \\
\hline CF/SAL & 0.0186 & 0.0070 & 0.0330 & 0.0597 & - \\
\hline \multicolumn{6}{|c|}{ 1996-1995 } \\
\hline$E M P$ & - & 0.9057 & 0.9506 & 0.8183 & 0.0160 \\
\hline SAL & 0.8062 & - & 0.9413 & 0.8267 & 0.0032 \\
\hline$V A$ & 0.7335 & 0.8281 & - & 0.7433 & -0.0072 \\
\hline$C F$ & 0.3442 & 0.4511 & 0.4746 & - & 0.6858 \\
\hline CF/SAL & 0.0113 & 0.0012 & -0.0096 & 0.3661 & - \\
\hline
\end{tabular}

$C F$, cash flow; $E M P$, employees; $S A L$, sales; $V A$, value added.

\section{Evidence from panel-data regressions}

In this section we present the results of regression analyses performed on our pooled sample of observations. We begin by a standard LPE estimation exercise where firm growth is regressed against logs of firm size at the beginning of the period, firm age at 


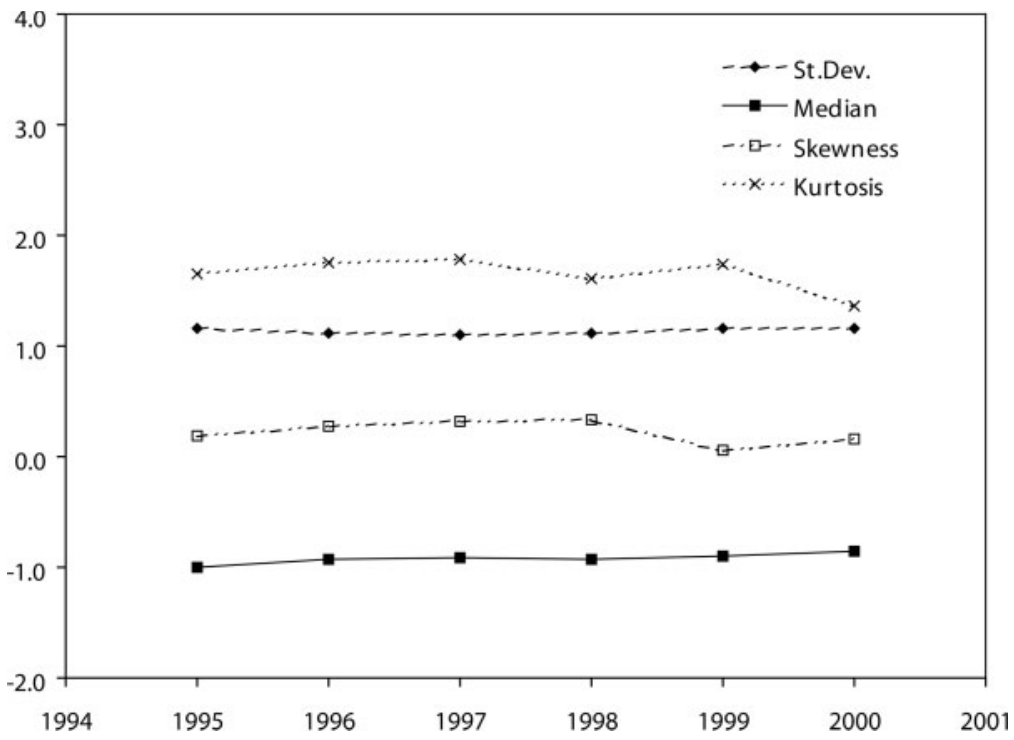

Figure 1 Moments of $\log \left(E M P_{i, t} / \overline{E M P}_{i, t}\right)$ distribution against time.

Table 4 Summary statistics for year-standardized pooled variables

\begin{tabular}{|c|c|c|c|c|c|}
\hline & Observation & Mean & SD & Skewness & Kurtosis \\
\hline$E M P \_G R$ & 71,380 & 0.0394 & 0.2221 & 0.8963 & 26.3321 \\
\hline $\log (E M P)$ & 71,382 & 0.0346 & 1.2921 & -0.7437 & 2.7124 \\
\hline SAL_GR & 71,385 & 0.0387 & 0.3270 & 0.7696 & 65.8774 \\
\hline $\log (S A L)$ & 71,385 & -0.9723 & 1.0460 & 1.0193 & 5.5047 \\
\hline$V A \_G R$ & 70,767 & 0.0461 & 0.3192 & 0.1655 & 45.6623 \\
\hline $\log (V A)$ & 71,091 & -0.9778 & 1.1791 & 0.7668 & 5.8549 \\
\hline $\log (C F)$ & 71,385 & -1.1187 & 1.6984 & 0.7474 & 4.8691 \\
\hline CF/SAL & 71,215 & 0.8956 & 3.4897 & 154.0042 & 28210.68 \\
\hline
\end{tabular}

$C F$, cash flow; $E M P$, employees; $G R$, growth rate; $S A L$, sales; $V A$, value added.

the beginning of the sample period, as well as non-linear size-age effects (e.g., size and age squared) and lagged values of both firm growth and size (Evans, 1987; Hall, 1987). We then introduce financial constraints by adding scaled cash flow $\left(S C F_{i, t}\right)$ to the regression (and lagged values thereof).

We employ non-standardized, pooled values while controlling for time fixed effects $\left(D_{\text {time }}\right)$. We also control for industry effects $\left(D_{\text {ind }}\right)$, defined according to 
Table 5 Correlation matrix for year-standardized pooled variables

\begin{tabular}{lrrrllll}
\hline Correlation & EMP_GR & $\log (E M P)$ & \multicolumn{1}{c}{ SAL_GR } & $\log (S A L)$ & VA_GR & $\log (V A)$ & $\log (C F)$ \\
\hline $\log (E M P)$ & -0.1150 & 1.0000 & \multicolumn{1}{c}{-} & - & - & - & - \\
SALGR & 0.2674 & -0.0182 & 1.0000 & - & - & - & - \\
Log(SAL) & 0.0029 & 0.7604 & -0.0942 & 1.0000 & - & - & - \\
VA_GR & 0.2498 & -0.0349 & 0.5409 & -0.0575 & 1.0000 & - & - \\
$\log (V A)$ & -0.0077 & 0.9016 & -0.0465 & 0.8647 & -0.1293 & 1.0000 & - \\
$\log (C F)$ & 0.0263 & 0.6778 & -0.0295 & 0.7543 & -0.0481 & 0.8240 & 1.0000 \\
CF/SAL & 0.0276 & 0.1143 & 0.1247 & 0.0197 & 0.0430 & 0.1837 & 0.4111 \\
\hline
\end{tabular}

$C F$, cash flow; $E M P$, employees; $G R$, growth rate; $S A L$, sales; $V A$, value added.

14 industry macro-classes, and for a "subsidiary" dummy $\left(D_{\text {subs }}\right)$ accounting for companies which are controlled by more than $50 \%$. This allows us to check whether affiliation to a large corporate relaxes financial constraints.

Lagged values of both size and growth (as well as $S C F_{i, t-k}, k>2$, and interactive terms such as $A G E \times E M P$ ) never appear to be significant in our regressions. We then start from the "saturated" model:

$$
\begin{aligned}
E M P_{-} G R_{i, t}= & \alpha_{1} \log \left(E M P_{i, t-1}\right)+\alpha_{2} S C F_{i, t-1}+\alpha_{3} \log \left(A G E_{i}\right) \\
& +\alpha_{4} \log ^{2}\left(E M P_{i, t-1}\right)+\alpha_{5} \log ^{2}\left(A G E_{i}\right)+\alpha_{6} S C F_{i, t-2} \\
& +\alpha_{7} D_{\text {time }}+\alpha_{8} D_{\text {ind }}+\alpha_{9} D_{\text {subs }}+\varepsilon_{i, t},
\end{aligned}
$$

where $\varepsilon_{i, t}$ is a white-noise term.

We rely on likelihood ratio tests (LRTs) to drop in each step one (or more) covariate(s) and eventually get to our preferred model. As shown in Table 6, this selection procedure allows us to discard both $\log ^{2}\left(A G E_{i}\right)$ and $\log \left(A G E_{i}\right)$ at $5 \%$ significance level. We also employ an alternative model selection procedure based on maximization of (pseudo) $R^{2}$ s (see Table 7 ). We begin by standard growth-size regressions (LPE) and we compare models obtained by adding covariates. Among all possible specifications, we show results of regressions that reach the highest $R^{2}$ values (which is always very low due to the large number of observations). This combined procedure suggests that, by omitting $\log \left(C F_{i, t-2}\right)$ from the "saturated" model, one gets the highest $R^{2}$ levels. However, if one also drops $\log ^{2}\left(A G E_{i}\right)$ and $\log \left(A G E_{i}\right)$ —as suggested by LRTs - the goodness of fit does not decrease very much. Therefore, the two criteria taken together indicate the following "preferred" model: 
Table 6 Model selection: results of the likelihood ratio (LR) test procedure

\begin{tabular}{|c|c|c|c|c|}
\hline \multirow[t]{2}{*}{ Regressors dropped } & \multicolumn{2}{|l|}{ First step } & \multicolumn{2}{|l|}{ Second step } \\
\hline & LR test & $R^{2}$ & LR test & $R^{2}$ \\
\hline $\log \left(E M P_{i, t-1}\right)$ & $750.84 * *(0.0000)$ & 0.0095 & $830.73^{* *}(0.0000)$ & 0.0070 \\
\hline$C F_{i, t-1} / S A L_{i, t-1}$ & $9.21 * *(0.0024)$ & 0.0226 & $9.52 * *(0.0020)$ & 0.0214 \\
\hline $\log \left(A G E_{i}\right)$ & $2.19(0.1388)$ & 0.0225 & Dropped in first step & \\
\hline $\log ^{2}\left(E M P_{i, t-1}\right)$ & $533.76^{* *}(0.0000)$ & 0.0132 & $573.90 * *(0.0000)$ & 0.0115 \\
\hline $\log ^{2}\left(A G E_{j}\right)$ & $0.32(0.5689)$ & 0.0226 & Dropped in first step & \\
\hline$C F_{i, t-2} / S A L_{i, t-2}$ & $8.62 * *(0.0033)$ & 0.0224 & $9.26^{* *}(0.0023)$ & 0.0214 \\
\hline$D_{\text {subs }}$ & Yes** & & Yes** & \\
\hline$D_{\text {ind }}$ & Yes** & & Yes** & \\
\hline$D_{\text {time }}$ & Yes** & & Yes** & \\
\hline
\end{tabular}

$C F$, cash flow; $E M P$, employees; $S A L$, sales.

Each row reports the results of the LR test for the null hypothesis: "Drop from the saturated model (i.e. the model containing all regressors not previously dropped) the regressor indicated in the first column." A double (single) asterisk associated to the LR test value indicates that the regressor must not be dropped at 5\% (10\%). Boldface values indicate regressors dropped.

$$
\begin{aligned}
E M P_{-} G R_{i, t}= & \beta_{1} \log \left(E M P_{i, t-1}\right)+\beta_{2} S C F_{i, t-1}+\beta_{3} \log ^{2}\left(E M P_{i, t-1}\right) \\
& +\beta_{4} D_{\text {time }}+\beta_{5} D_{\text {ind }}+\beta_{6} D_{\text {subs }}+\varepsilon_{i, t}
\end{aligned}
$$

Estimation of equation (5) shows that size effects are significant and negative (Lotti et al., 2003). Our data therefore confirm a rejection of the LPE: smaller firms grow more, even when one controls for financial constraints. In addition, firms with higher cash flow ratios enjoy higher growth rates, once one controls for sheer size. A positive and significant non-linear size effect is present. Notice that introducing $\log ^{2}\left(E M P_{i, t-1}\right)$ in the regression also implies a higher magnitude for the growth-size correlation. Our results also suggest that younger firms experience higher growth rates, as shown by a significant negative effect of $\log \left(A G E_{i}\right)$ in Table 7 . Anyway, this effect does not seem to be pivotal in our model, as indicated by the LR test procedure. The "subsidiary" dummy is significant in all model specifications, suggesting that, given the same degree of liquidity constraints, firms which belong to a large company grow more than independent firms, possibly because of an easier access to external financing.

The above findings are in line with previous ones obtained by Carpenter and Petersen (2002) on US data, which show that small surviving firms experience higher growth rates, but these are negatively affected by firm financial constraints, where the 


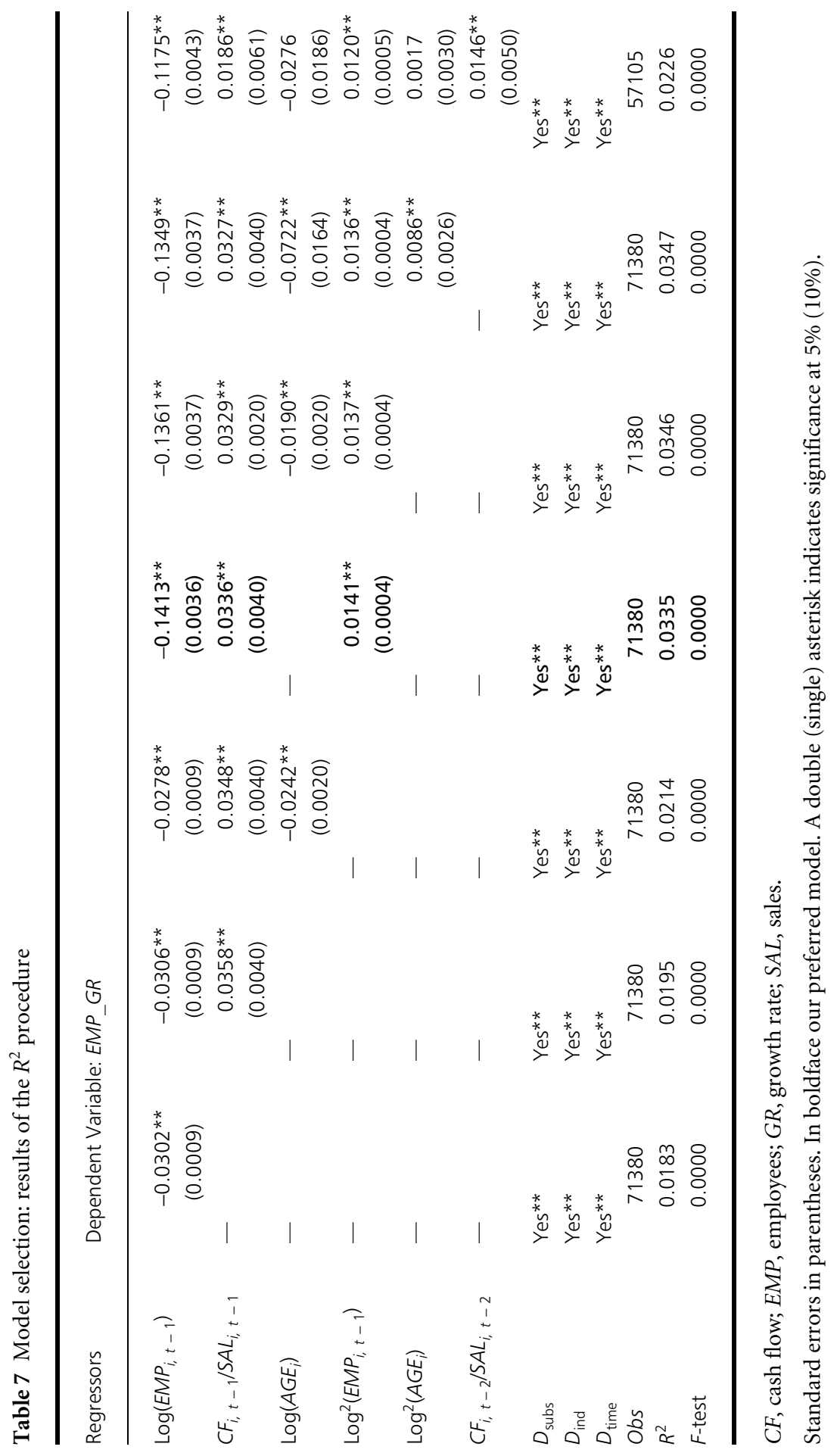


latter are proxied by scaled cash flow measures. Becchetti and Trovato (2002) reach similar conclusions on a sample of Italian firms. In particular, they show that small firms grow more, but growth rates are negatively affected by the availability of external finance (proxied by leverage measures and by a dummy variable indicating if firms received any soft loans or grants in the observed period) and by financial constraints, which are proxied in their analysis by a qualitative variable from survey data saying if the firm asked for additional credit and was actually denied. On the contrary, Audretsch and Elston (2002) show that medium sized German firms are more liquidity constrained (in their investment behavior) than either the smallest or the largest ones. ${ }^{18}$

Our results seem to be robust vis-à-vis a number of different checks. First, although lagged values of SCF should be in principle important to explain current growth, our data suggest that $S C F_{i, t-k}, k \geq 2$, is hardly significant in the saturated model (see also last column in Table 7) and that any statistical significance is only due to the large number of observations we have in our data set. ${ }^{19}$ Second, if we only consider "financially-related" size effects and we exclude sheer size effects-that is, if we discard $\log \left(E M P_{i, t-1}\right)$-in our regressions, scaled cash flow remains significant and positive. This seems to be a strong indication in favor of the robustness of this measure as a proxy for firm financial constraints. Third, both significance levels and signs of estimates do not change if we consider year-standardized variables and omit fixed time effects in the regressions. Fourth, if one also controls for EMP_GR ${ }_{i, t-1}$ in the preferred model, all estimates remain significant and their signs do not change. The lagged growth term appears to be significant but in general its magnitude turns out to be quite small. Fifth, although firms heterogeneity was taken into account only through industry-specific effects, our main results do not change if we estimate a within transformation (WT) version of our preferred model (without industry dummies) to take into account both firms and time fixed effects. In particular, if we regress (using the WT) the $\log$ of size at $t$ on the $\log$ of size at $t-1$ and the scaled cash flow at $t-1$, we find that ${ }^{20}$

$$
\log \left(E M P_{i, t}\right)=\underset{(0.0010)}{0.0166} \cdot \log \left(E M P_{i, t-1}\right)+\underset{(0.0171)}{0.0881 \cdot S C F_{i, t-1}}
$$

\footnotetext{
${ }^{18}$ Elston (2002) finds that cash flow (not scaled) positively affects growth of German Neuer-Markt firms-after controlling for size and age. We find similar results in our sample too, using scaled cash flow measures. However, her outcome may be biased by the high and positive correlation between size (employees) and cash flow.

${ }^{19}$ Although we decided to drop lagged SCF values here, an in-depth investigation of their effects-as well as of those of cumulated SCF values - is certainly one of the main points in our agenda.

${ }^{20}$ In both regressions (6) and (7) we have $N=71,380$ and $R^{2} \simeq 0.005$. All coefficients are significant at $1 \%$. Standard errors in parentheses. $F$-tests are always rejected at $1 \%$. In regression (6), as happens in the previous analysis with industry dummies and no firms fixed effects, cash flow exerts its effect also if it is not scaled by size (see section 2 ).
} 
so that we still observe that firm growth rates decrease with size $\left(\hat{\beta}_{1}=0.0166<1\right)$ and firms with higher cash flow grow more. More precisely, if we estimate our preferred model in equation (5) using a WT, we obtain the following:

$$
\begin{aligned}
E M P_{-} G R_{i, t}= & \underset{(0.0267)}{-0.9134} \cdot \log \left(E M P_{\mathrm{i}, t-1}\right)+\underset{(0.0153)}{0.0711 \cdot S C F_{\mathrm{i}, t-1}} \\
& +\underset{(0.0042)}{0.0435 \cdot \log ^{2}\left(E M P_{\mathrm{i}, t-1}\right)}
\end{aligned}
$$

The effect of age is spanned out once we control for time and firms fixed effects in the model. ${ }^{21}$ Indeed, once the WT is applied to the age covariate and the time covariate, entering fixed effects for firms and for time periods naturally makes it unnecessary (and not possible) to separately control for age. Following Carroll and Hannan (1999) and Barron et al. (1994), we also try a different specification for the measurement of the effect of age in a WT model. ${ }^{22}$ Also in this case, the effect of age is weaker with respect to the model estimation with no firm fixed effects (model 4). Indeed, while age continues to exert a negative and significant effect on growth rates unconditional on firm size, its effect becomes not significant when we reintroduce size into the regression. ${ }^{23}$ The only source of heterogeneity-other than the one captured by firm specific effects-is given in this case by firm size and by our proxy for firm financial constraints.

Let us now turn to further explore some important issues concerning the relationship between age and financial constraints in our sample data. Despite age does not exhibit a pivotal effect according to the LR test when we control for scaled cash flow (see Table 6), the LR test for the saturated model with no scaled cash flow (and no lagged values) does not suggest to drop age (see Table 8 ). ${ }^{24}$ Age, conditional on size, seems to play a major role in the analysis when we do not control for firm financial constraints. Age effects become instead weaker once we insert in the regression cash flow scaled by firm size. We find this result quite consistent with the model proposed by Cooley and Quadrini (2001) in the framework of the recent theoretical literature on financial market frictions and firm performance. Starting from an Hopenhayn (1992) model specification with only persistent shocks to technology, the authors show that firm age, conditional on size, significantly influences growth if also financial frictions are inserted in the model. Consequently, if age

\footnotetext{
${ }^{21}$ Note that similar results are obtained if we consider a model specification with firms fixed effects and where calendar time is fit with just a couple of dummies instead of one dummy for each year.

${ }^{22}$ We alternatively employ $\log (A g e)$ as a regressor or a piecewise exponential specification inserting $\log \theta(a)$ in our model, where $\theta(a)=\exp \left(\sum_{k=1}^{K} \mu_{k} i_{k}\right)$ and the age range is divided by $K$ points $\left(i_{k}\right.$ represents a dummy variable equal to 1 if the firm age is in range $\left[a_{k-1}, a_{k}\right]$ and $\mu_{k}$ represents the baseline growth rate which is constant within the same age range).

${ }^{23}$ Results from this unreported regression are available from the authors upon request.

${ }^{24} \mathrm{We}$ are grateful to an anonymous referee for suggesting us to elaborate on this point.
} 
Table 8 Results of the likelihood ratio (LR) test procedure in a model specification that does not control for firm financial constraints

\begin{tabular}{lll}
\hline Regressors dropped & First step & \\
\cline { 2 - 3 } & LR test & $R^{2}$ \\
\hline $\log \left(E M P_{i, t-1}\right)$ & $750.84^{* *}(0.0000)$ & 0.0095 \\
$\log \left(A G E_{i}\right)$ & $20.89^{* *}(0.0000)$ & 0.0334 \\
$\log ^{2}\left(E M P_{i, t-1}\right)$ & $896.29^{* *}(0.0000)$ & 0.0208 \\
$\log ^{2}\left(A G E_{i}\right)$ & $400.16^{* *}(0.0000)$ & 0.0335 \\
$D_{\text {subs }}$ & Yes $^{* *}$ & \\
$D_{\text {ind }}$ & Yes $^{* *}$ & \\
$D_{\text {time }}$ & Yes $^{* *}$ & \\
\hline
\end{tabular}

EMP, employees.

Each row reports the results of the LR test for the null hypothesis: "Drop from the saturated model (i.e. the model containing all regressors not previously dropped) the regressor indicated in the first column." A double (single) asterisk associated to the LR test value indicates that the regressor must not be dropped at 5\% (10\%).

represents a proxy for financial constraints, we expect that its effects would fade away when growth rates are related with more precise financial measures. In unreported regressions, we further explore this line of reasoning finding that in our sample the estimated coefficient of cash flow is larger in magnitude for younger firms, highlighting that a financial factor is really correlating with firm age: the growth rates of younger firms are more sensitive to cash flow levels. This implies that if younger firms are heavily selected on the market for financing, only the more productive ones will find resources to fuel their growth process. The overall picture suggested by these analyses is a complex one, where financial constraints, age, and expected growth rates coevolve in non-trivial ways. Despite the limited time span of our sample prevents us to test for this conjecture, our preliminary results seem to go in the direction of the more recent theoretical and empirical literature.

The evidence discussed so far supports the idea that firm growth is negatively affected by both size and liquidity constraints. Moreover, the negative relationship between age and growth, once one controls for size, can be explained as an effect due to the presence of financial frictions in the market. However, the goodness-of-fit of our preferred model is not very encouraging. In presence of such low $R^{2}$ s (and quite small estimated coefficients), one might also be tempted to conclude that, albeit significant, the effect of size and scaled CF on average growth rates is irrelevant (at least as far as policy issues are concerned). ${ }^{25}$ In order to further explore whether our data really exhibit

\footnotetext{
${ }^{25}$ For a discussion on the interpretation of LPE empirical results see Sutton (1997) and Geroski (2000).
} 
departures from the LPE, we now turn to a more detailed statistical analysis of pooled size and growth distributions. We shall investigate in particular the properties of the joint growth-size distribution conditional on scaled cash flow observations.

\section{Statistical properties of pooled size and growth distributions}

If the benchmark model of stochastic firm growth underlying the LPE holds true, then for any measure of firms size $S_{t}$, the dynamics of $S_{t}$ reads

$$
S_{t}=S_{t-1} R_{t}
$$

where $R_{t}$ is a random variable. If $r_{t}=\log R_{t}$ are i.i.d. random variables with finite mean and variance, then $S_{t}$ is well approximated, for sufficiently large $t$, by a log-normal distribution. Moreover, growth rates $g_{t}=\Delta \log \left(S_{t}\right)$ should be normally distributed.

We then begin by checking whether our pooled (year-standardized) firm size distributions depart from log-normal ones. As size-rank plots suggest, the distributions of $\widetilde{E M P}, \widetilde{S A L}$, and $\widetilde{V A}$ can hardly be approximated by a log-normal (cf. Figure 2 for the evidence about employees), as the mass of these distributions seems to be shifted to the left. As Figure 2 shows, a similar finding holds for $\widetilde{S C F}$ as well. ${ }^{26}$

Furthermore, pooled standardized growth rates appear to follow a tent-shaped distribution, with tails fatter than those of a Gaussian one (cf. Figure 3). Growth rate distributions are indeed well described by a Laplace (symmetric exponential) functional form:
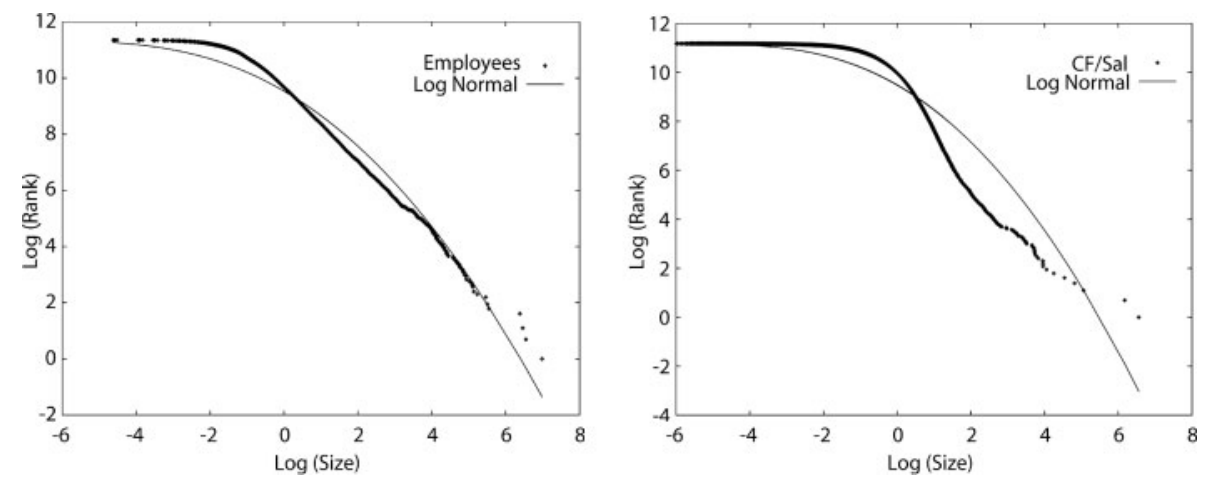

Figure 2 Pooled (year-standardized) employees (left) and cash flow (CF)/sales (right) distributions. Log rank versus log size plots.

\footnotetext{
${ }^{26}$ These results are also confirmed by non-parametric kernel estimates (performed using a normal kernel with a 0.2 bandwidth) of size and $\widetilde{S C F}$ densities. Results are available from the authors upon request.
} 


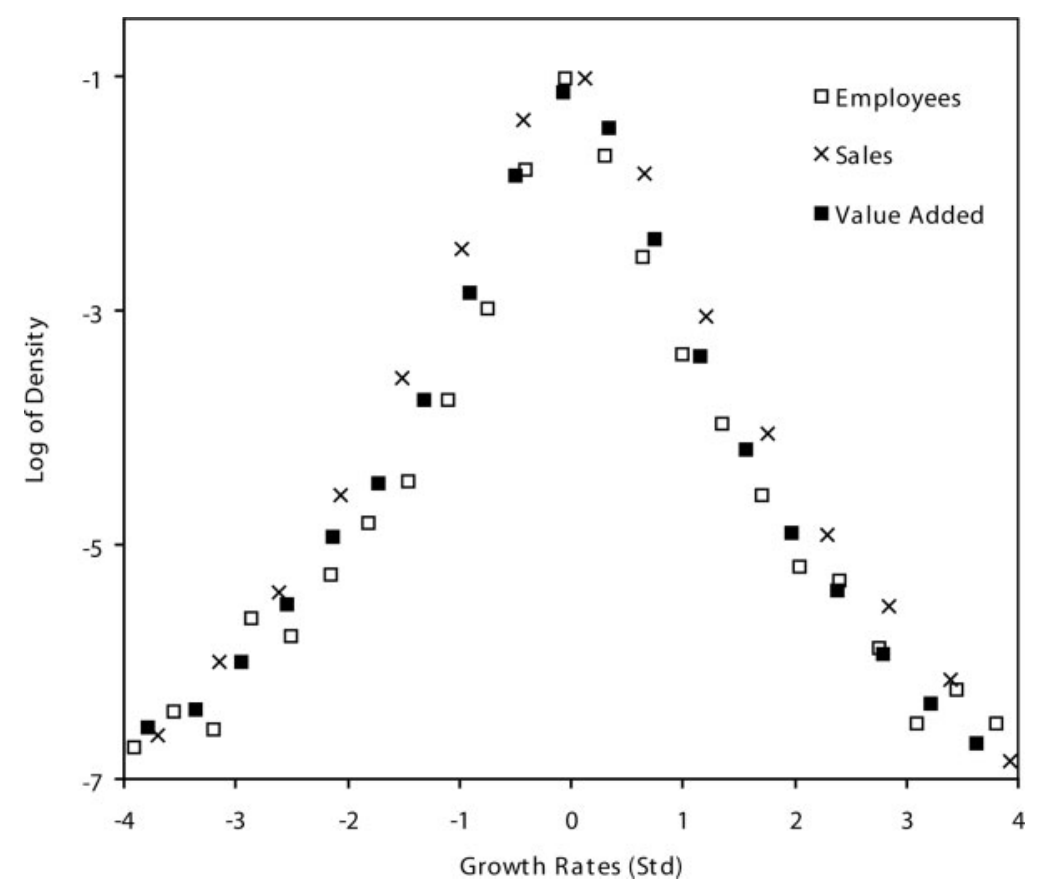

Figure 3 Pooled (year-standardized) firm growth rates. Binned empirical densities versus Laplace fit.

$$
h(x ; a, b)=\frac{1}{2 a} e^{-\frac{|x-b|}{a}},
$$

where $a>0$. Tent-shaped distributions have been recently found to robustly characterize growth rates both at an aggregated level (Stanley et al., 1996; Amaral et al., 1997) and across different industrial sectors and countries (Bottazzi and Secchi, 2003a, b).

The foregoing two pieces of evidence (i.e., departures from log-normality of size distributions and fat tailed, tent-shaped, growth rate distributions) suggest that the underlying growth-size dynamics is not well described by a simple Gibrat-type process with independent increments. This conclusion is further reinforced by looking at how growth average and standard deviation vary with average (within bins) firm sizes. ${ }^{27}$ As already found in regression exercises, small firms seem to grow more on average, but their growth patterns appear to be more volatile than those of larger firms. This holds true for all measures of size (cf. Figure 4 for the employees distribution). In fact, one

\footnotetext{
${ }^{27}$ In this and all subsequent plots, we do not depict confidence intervals as they typically lie very close to the statistics values.
} 


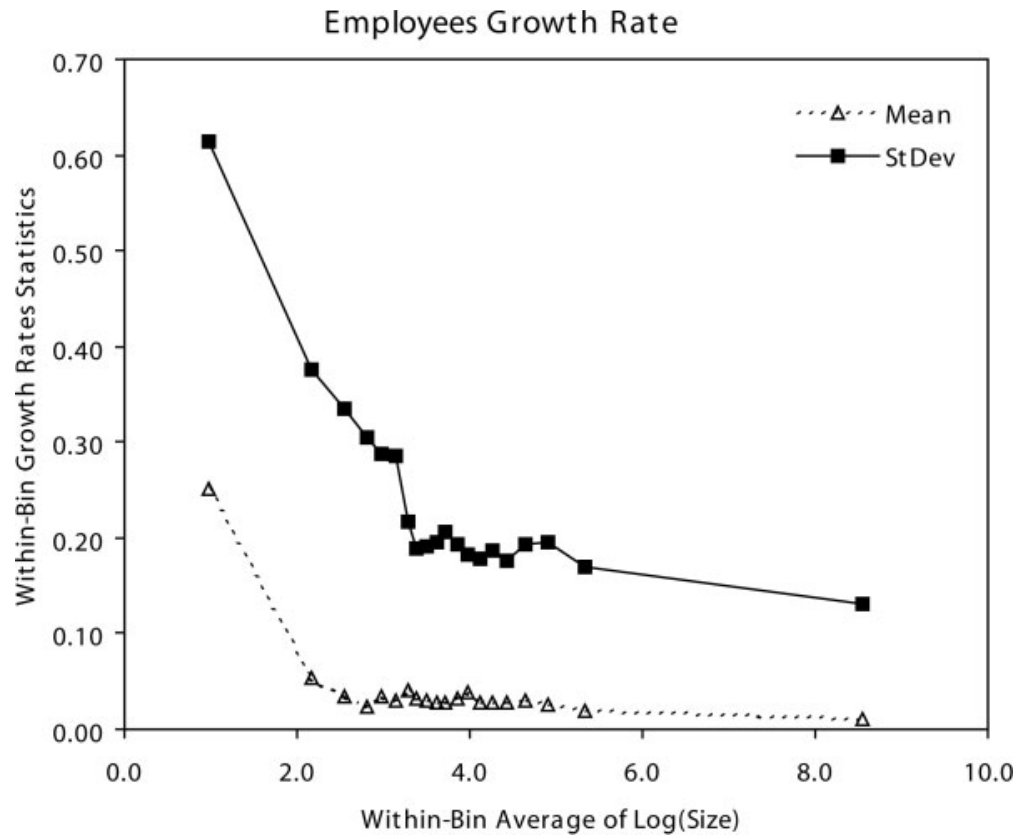

Figure 4 Mean and standard deviation of pooled (year-standardized) employees growth rates as a function of (within-bins) average $\log ($ size). Bins computed as 5 percentiles.

typically observes a rapidly declining pattern for both average and variance of growth rates as size increases, which, however, stabilizes for larger firm size values. ${ }^{28}$

But how do liquidity constraints affect the joint size-growth distribution? To explore this issue, we investigated how average and standard deviation of size $(\log \widehat{E M P})$ and growth $\left(\widetilde{E M P} \_G R\right)$ pooled distributions (as well as their correlation) change with respect to (within-bins) averages of $\widetilde{S C F}{ }^{29}$

\footnotetext{
${ }^{28} \mathrm{~A}$ similar result is obtained if one splits the pooled sample of firms into "small" (e.g., those belonging to the first quartile) versus "large" ones (e.g., those belonging to the fourth quartile) and separately estimates our preferred regression model on each sub-sample. Indeed, the LPE seems to hold for large firms but fails for small ones. This conclusion is quite robust to alternative ways of splitting the pooled sample into large versus small firms.

${ }^{29}$ More formally, given the triple distribution $\left(\widetilde{E M P} \_G R_{t}, \log \widetilde{E M P_{t-1}}, \widetilde{S C F_{t-1}}\right)$, we computed statistics of $\left(\widetilde{E M P} P_{-} G R_{t}, \log \widetilde{E M P_{t-1}}\right)$ for each $5 \%$ percentile of $\widetilde{S C F}_{t-1}$. The qualitative implications we present in this section are not dramatically altered if one employs non-standardized values. Notice also that, in line with our analysis in Section 3, we do not consider further lags for our SCF variable. An interesting extension would be to study the moments of the multivariate distribution $\left(\widetilde{E M P} \_G R_{t}, \log {\widetilde{E M P_{t-1}}}_{S C F_{t-1}}, \ldots, \widetilde{S C F}_{t-d}\right)$, where $d \geq 2$.
} 
Our exercises point out that-in line with regressions results-firms facing stronger liquidity constraints are associated with lower average growth and smaller average size (Figure 5). We also find that smaller cash flows imply more volatile growth patterns while no clear implications can be drawn as far as within-bins size variability is concerned (Figure 6).

As a consequence, one observes statistically detectable differences in both size and growth distributions associated to strongly versus weakly liquidity-constrained (WLC) firms. As Figure 7 (left) shows for the first and the tenth decile of $\widetilde{S C F}$, less liquidity constrained firms exhibit size distributions which are substantially shifted to the right. Once one controls for any mean-variance shift and compares standardized size
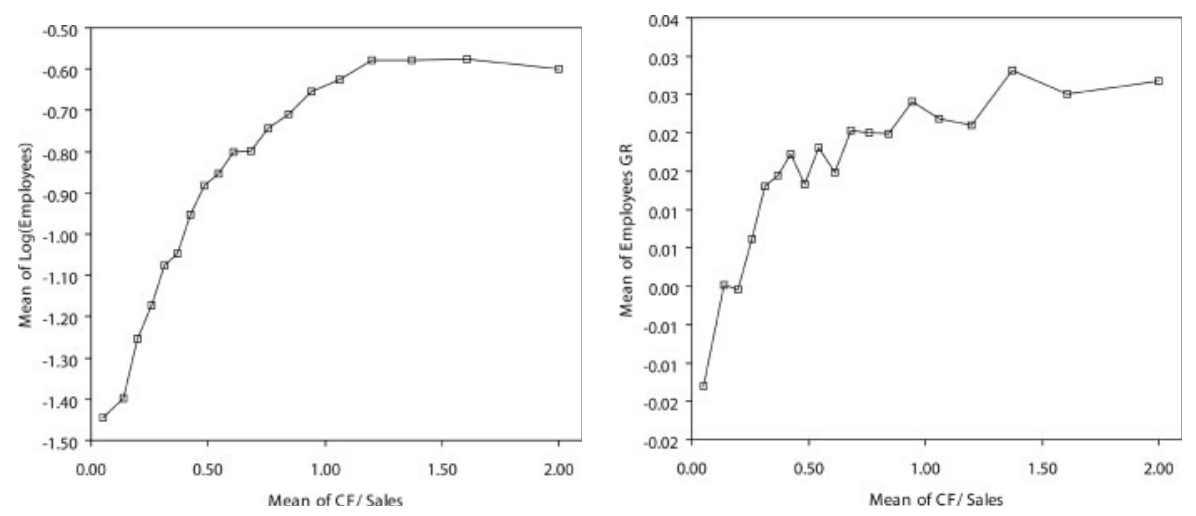

Figure 5 Mean of pooled (year-standardized) size (left) and growth rates (right) distributions as a function of (within-bins) average cash flow (CF)/sales. Bins computed as 5 percentiles.
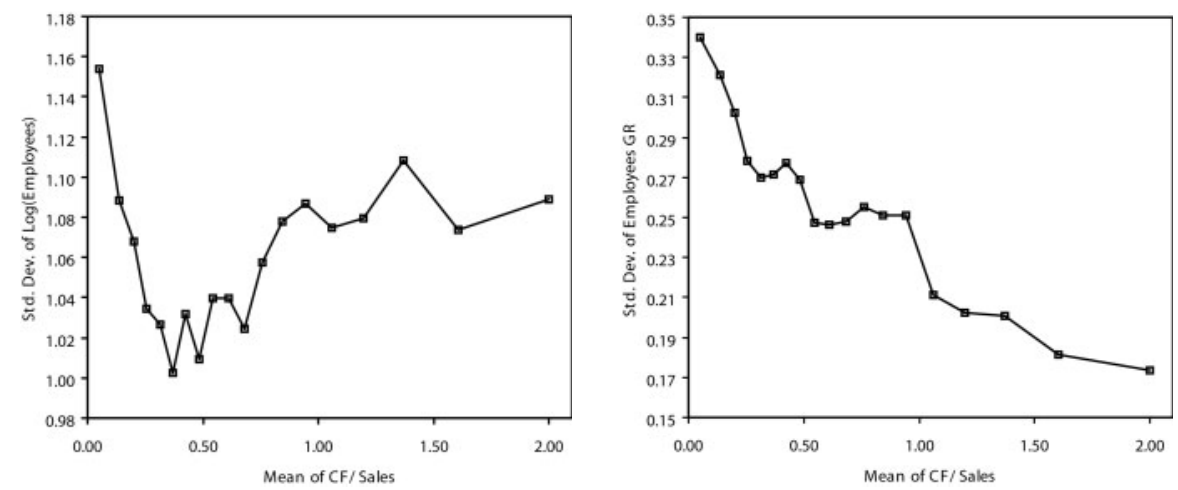

Figure 6 Standard deviation of pooled (year-standardized) size (left) and growth rates (right) distributions as a function of (within-bins) average cash flow (CF)/sales. Bins computed as 5 percentiles. 

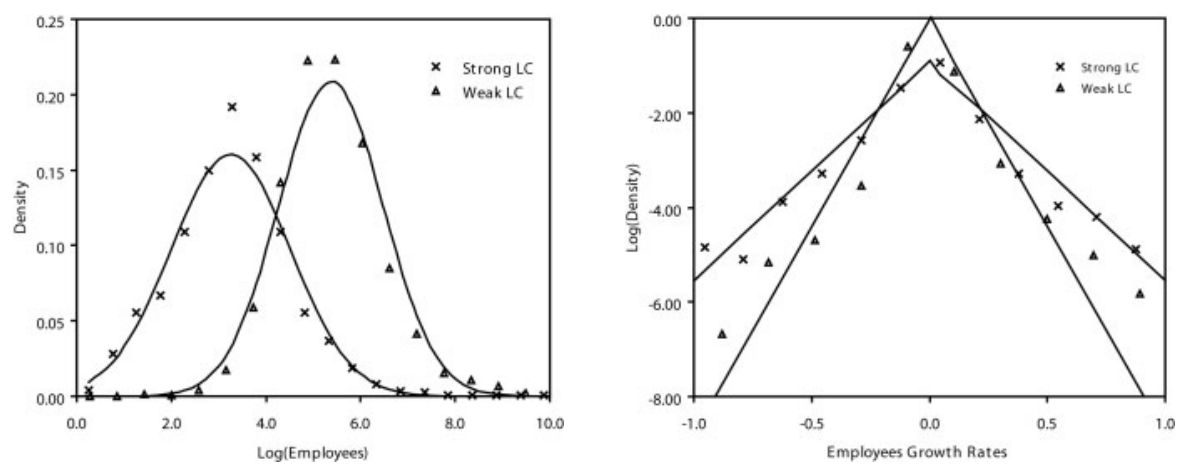

Figure 7 Pooled log of employees (left) and employees growth rate (right) distributions conditional to cash flow (CF)/sales. Strong liquidity constraints (LC) means $\mathrm{CF} /$ sales in the first decile. Weak LC means CF/sales in the tenth decile.

distributions (i.e., with zero-mean and unitary variance), any statistically detectable difference disappears.

Accordingly, growth rate distributions maintain their characteristic tent-shaped pattern but the estimated Laplace coefficient (i.e., the estimate for $a$ in eq. 9) decreases with cash flow: see Figure 7 (right). Notice that a lower Laplace coefficient (i.e., a steeper Laplace fit) might be interpreted as evidence in favor of fatter-tailed growth distributions, as long as the variance of the distribution remains constant. ${ }^{30}$ Again, a comparison of standardized growth distributions (i.e., with zero-mean and unitary variance) associated to high versus low cash flow levels no longer reveals statistically detectable differences: estimated Laplace coefficients (cf. Figure 8) are nearly constant with respect to cash flow. The same pattern also emerges when one plots estimated Laplace coefficients against log of size (not shown).

Our data suggest that liquidity constraints do not dramatically affect the fatness of growth rates tails. Less liquidity-constrained firms do not enjoy high-probability (absolute values of) large growth shocks, as compared to more liquidity-constrained ones, after one controls for existing mean-variance trends.

Finally, growth-size correlation ${ }^{31}$ is always negative for all cash flow levels (Figure 9). Nevertheless, the stronger liquidity constraints, the stronger the effect of size on growth. Note also that within-bins correlation magnitudes are always significantly larger than the non-conditioned one (i.e., correlation computed across all SCF values).

\footnotetext{
${ }^{30}$ If $b=0$ and $X$ is distributed as a Laplace $(a)$, then $\operatorname{var}(X)=2 a^{2}$. Thus, smaller estimates for $a$ imply fatter tailed distributions only if one controls for their variance.

${ }^{31}$ Growth-size correlations computed here are not partial ones. Hence, they cannot be compared to regression results which include other explanatory variables.
} 


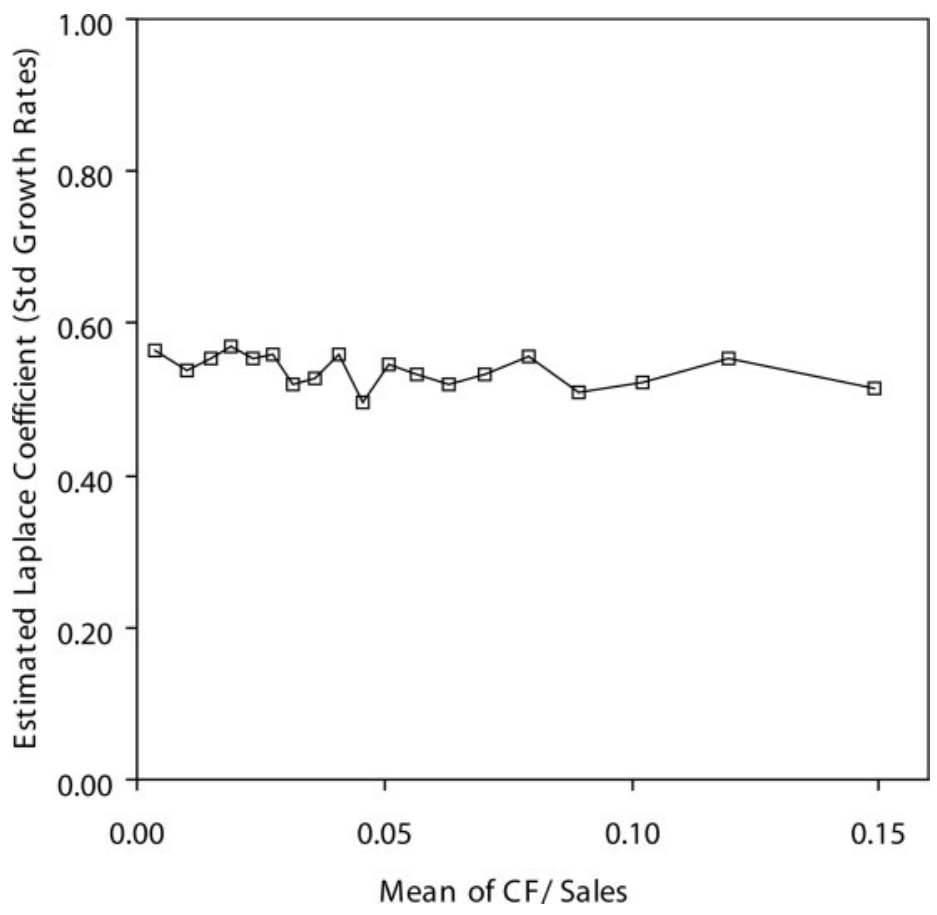

Figure 8 Estimated Laplace coefficients for Laplace fit of employees growth rates (zero-mean, unitary variance) conditional on (within-bins) averages of cash flow (CF)/sales. Bins computed as 5 percentiles.

\section{Liquidity constraints and the evolution of size-growth distributions over time}

In the last section, we characterized some statistical properties of pooled growth and size distributions conditioning on cash flow. We employed pooled data since we observed that, once one controls for year-averages, size and growth distributions are almost stationary over time. Yet, size and growth distributions do exhibit some trends in their moments, as Table 1 shows. In this section, we start exploring in more detail the nature of the observed shifts in non-standardized growth, size, and SCF distributions. Next, in Section 6, we shall investigate the effect of age on growth-size dynamics. We shall compare, in particular, the performance of firms which were more liquidity constrained and younger at the beginning of our sample period with that of firms which held larger SCF and were older.

Let us begin with unconditional size, growth, and scaled cash flow (non-standardized) distributions. Kernel estimates and statistical tests all confirm that no dramatic shifts over time are present in our data. All size year distributions (i.e., $E M P_{t}, S A L_{t}$, and $V A_{t}$, $t=1995, \ldots, 2000$ ) exhibit some shift to the right due to an increasing mean (due to overall economic growth) and become slightly more concentrated and less skewed to 


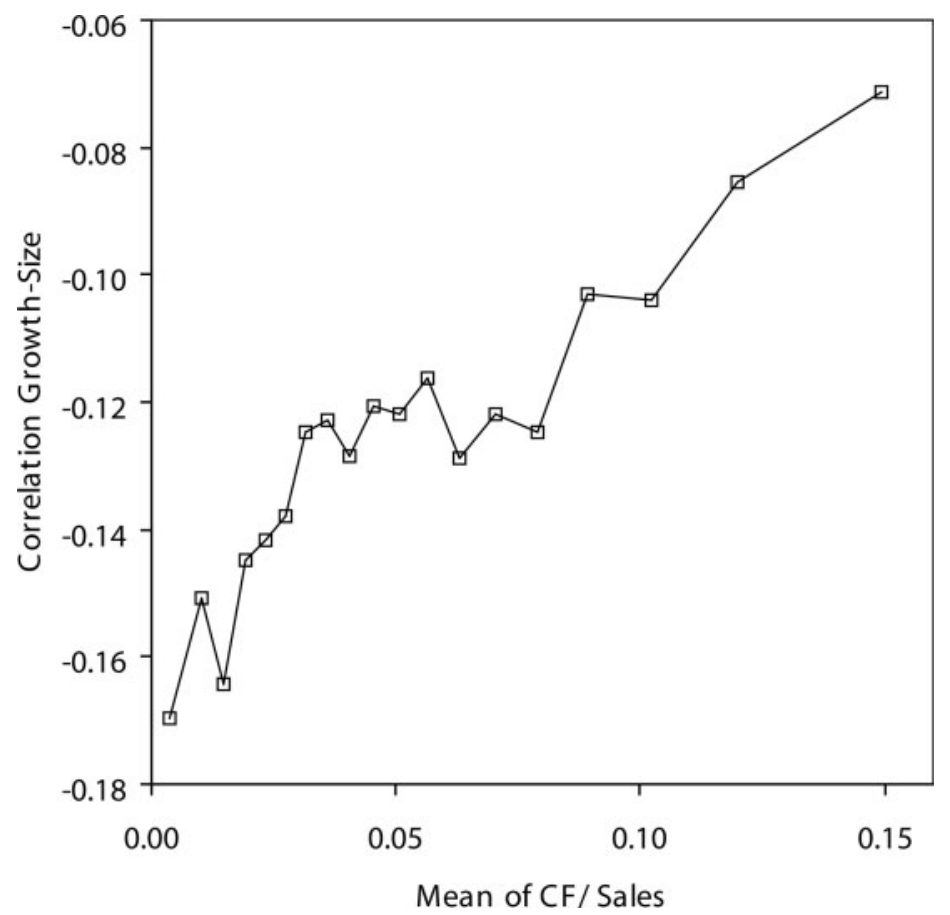

Figure 9 Correlation between $\log$ (employees) and employees growth rates conditional on (within-bins) averages of cash flow (CF)/sales. Bins computed as 5 percentiles.

the right (see Figure 10). Cash flow ratios seem to be even more stationary (cf. bottomright panel). Any observed shift seem, however, to be entirely due to changes in mean and variance over the years and disappear when one standardizes the variables.

Similar findings are obtained for growth rate distributions. Moments of EMP_GR $S A L \_G R_{t}$, and $V A \_G R_{t}(t=1996, \ldots, 2000)$ are almost stable across years (if any, average growth is $U$-shaped and growth rate standard deviations seem to decline over time). Tentshaped distributions emerge in all years and estimated Laplace coefficients are nearly stable. The unique exception concerns employee growth rate distributions, which exhibit tails becoming fatter with time. However, when one controls for mean and variance, esti-

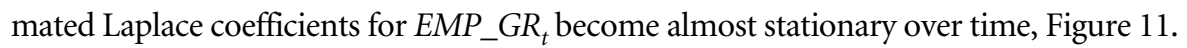

Consider now the evolution over time of size-growth distributions conditional on one-year lagged cash flow ratios, for example $\left(E M P_{-} G R_{t}, E M P_{t-1} \mid S C F_{t-1}\right) .{ }^{32} \mathrm{We}$ are interested in asking whether the evidence about the relationship between liquidity constraints and moments of size-growth distributions (e.g. average and standard deviation) that we obtained using pooled data (see Section 4) is robust to time disaggregation.

\footnotetext{
${ }^{32} \mathrm{We}$ employ $S C F_{t-1}$ only because the correlation with size and growth variables typically become almost irrelevant for $S C F_{t-k}, k>1$.
} 

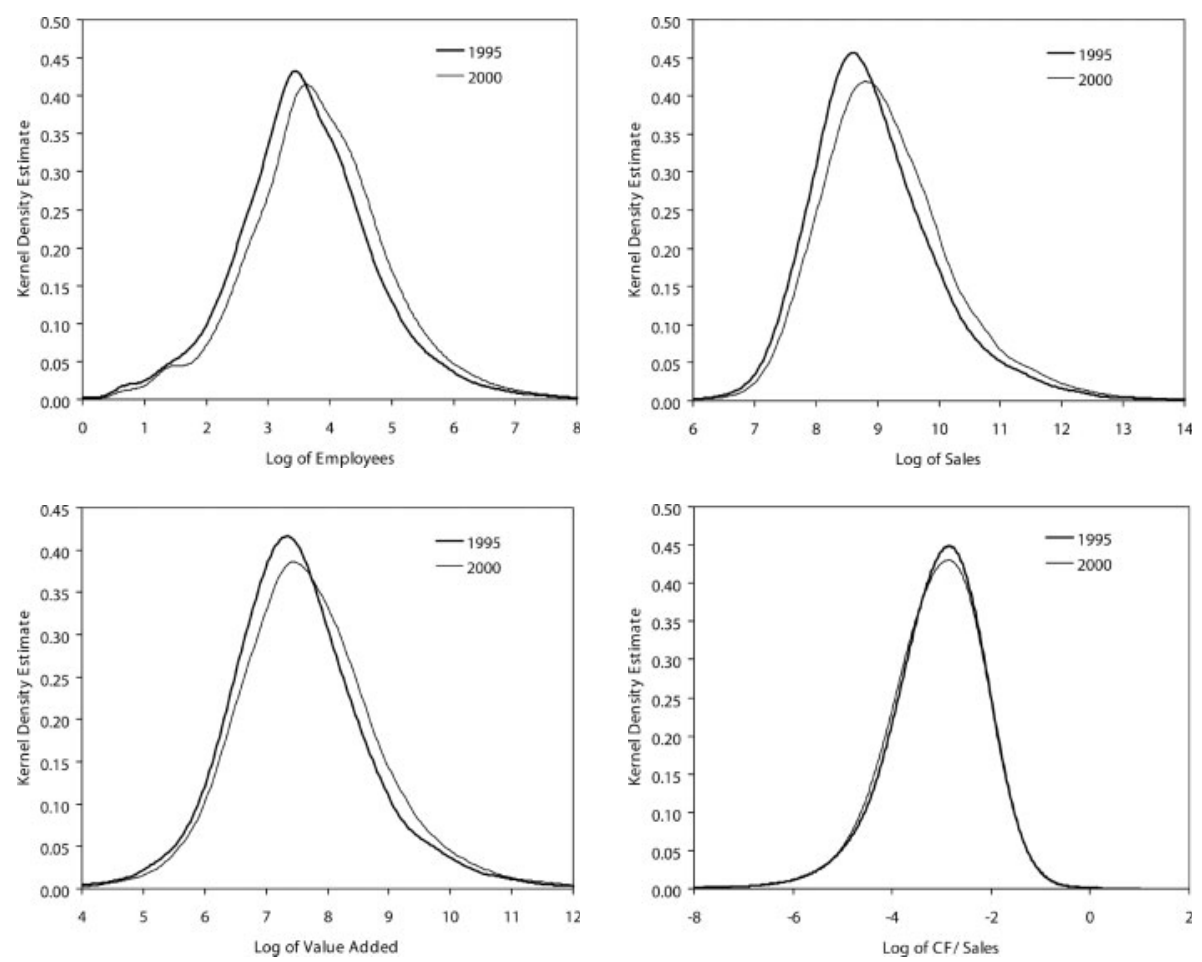

Figure 10 Non-parametric kernel density estimates of non-standardized size and cash flow (CF)/sales distributions. Top-left, employees; top-right, sales; bottom-left, value added; bottom-right, CF/sales (log scale). Kernel density estimates are performed employing a normal kernel and a 0.2 bandwidth.

Our results provide a mixed answer to this question. On the one hand, average size tends to increase in all years with cash flow (Figure 12, top-left, for the evidence about 1996 and 2000). On the other hand, average growth rates appear to be increasing with SCF only in 1996: as one approaches the end of our sample period, average growth rates seem to be constant with respect to liquidity constraints (Figure 12, bottom-left). Nevertheless, growth rates appear to be more volatile the smaller SCF (Figure 12, bottom-right) in every year taken into consideration. No clear indication, however, emerges as to whether strongly liquidity-constrained (SLC) firms enjoy less volatile size distributions (Figure 12, top-right).

Thus, the negative impact of liquidity constraints on firm growth, which was quite strong in our pooled sample, becomes more ambiguous when one disaggregates across years. We argue that an explanation for this result can be rooted in the way firms perceive liquidity constraints over the business cycle. If we do not wash away growth trends in the whole manufacturing sector, our data may still embed the effects 

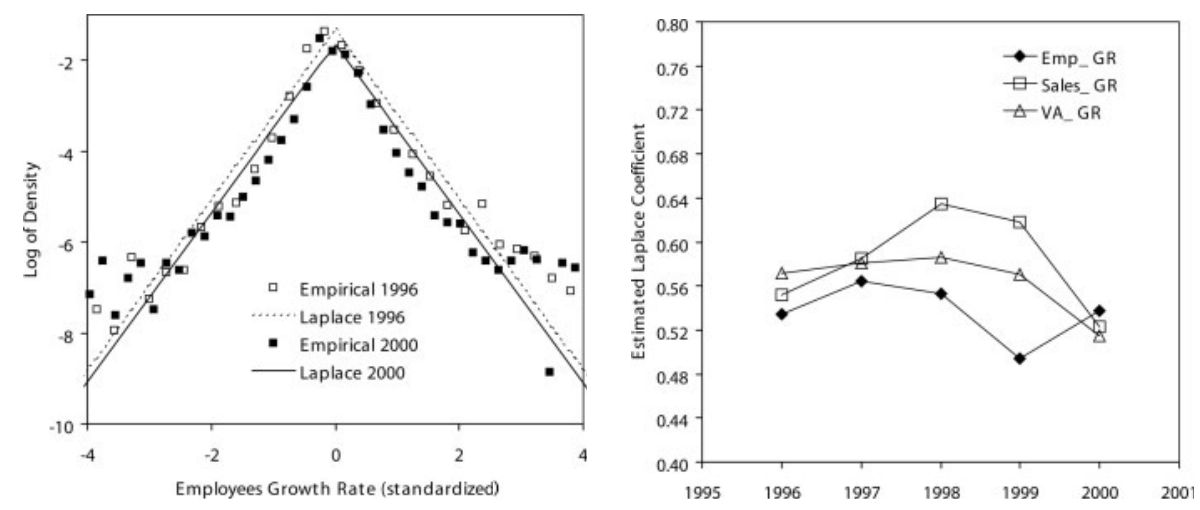

Figure 11 Shifts of growth rates distributions over time. Left, empirical distributions and Laplace fit for 1996 and 2000 standardized employees growth rate (GR) distributions (zero Mean, unitary variance). Right, estimated Laplace coefficient for 1996 and 2000 standardized employees, sales, and value-added GR distributions (zero mean, unitary variance).

of firms expectations about the impact of sheer size and liquidity on their future investments and growth. Since these expectations typically depend on the business cycle, one might well observe in our data different correlation patterns between financial constraints and growth across years.

All the other properties which we have found in our pooled sample robustly hold also for non-standardized data across time. For example, both size and growth distributions (conditional on SCF) are quite stable over time. As Figure 13 shows, size distributions for highly and WLC firms only shift to the right as we move from 1995 to 2000 while estimated Laplace coefficients for growth rate distributions do not exhibit any detectable time-difference when we compare high and low cash flow firms (Figure 14) after having controlled for their variance. In addition, the correlation between $E M P_{-} G R_{t}$ and $E M P_{t-1}$ remains always negative for each $t$ and each cash flow bin. The magnitude of the size-growth correlation turns out to be larger the stronger liquidity constraints are and appears to have substantially decreased in the sample period (see Figure 15).

\section{Size, age, liquidity constraints, and firm growth}

The evidence discussed at the end of the last section indicates that our panel of firms has somewhat shifted over time toward a Gibrat-like growth-size dynamics. The decrease of growth-size correlation across years is probably due to the overall growth experienced by the whole manufacturing sector in the sampled period (on average, all firms grew by $4.3287 \%$ from 1995 to 2000). On the one hand, evidence on pooled data suggests that small, younger, and WLC firms should have benefited from higher growth. On the other hand, smaller firms are typically younger but more 

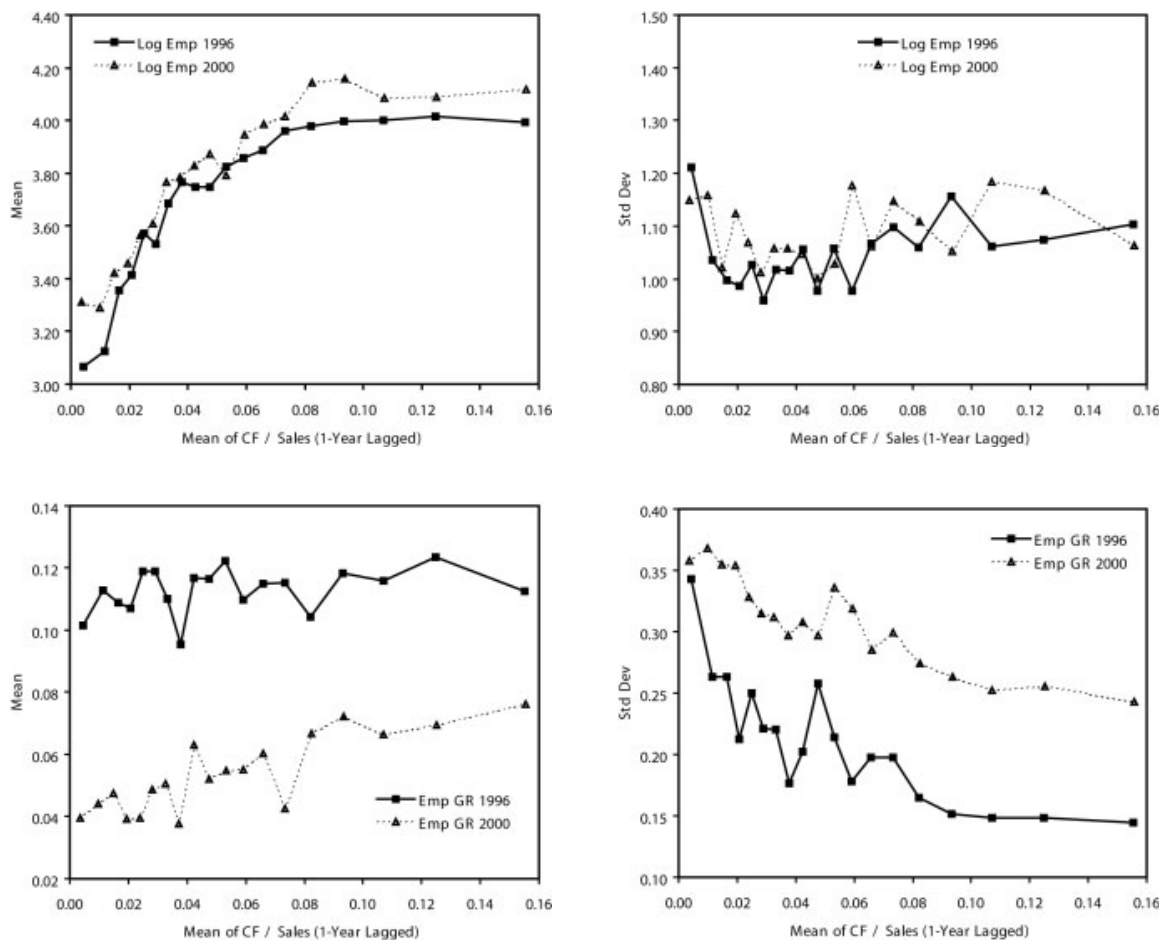

Figure 12 Average and standard deviation of employee size and growth year distributions conditioned on (within-bins) averages of (1-year lagged) cash flow (CF)/sales. Top-left, average of log of employees; top-right, SD of log of employees; bottom-left, average of employees growth rate (GR); bottom-right, SD of employees GR. Bins computed as 5 percentiles.

liquidity-constrained than larger ones. In addition, we observed that the negative correlation between liquidity constraints and growth may be weakened by time disaggregation.

Thus, an interesting issue concerns whether across-years performances of firms which were young but SLC at the beginning of the period could be larger than that experienced by firms which were older but held large cash flows. More generally, we are interested here in assessing whether firm age might allow us to better understand how liquidity constraints affect size growth patterns. In order to answer these questions, we start by analyzing how age affects cash flow ratios, size, and growth distributions over time.

To begin with, firm age in our database is log-normally distributed, as confirmed by both density estimates-see Figure 16-and Kolmogorov-Smirnov tests. Controlling for age only, we find that younger firms grow more, are smaller and more liquidity constrained as expected (Fazzari and Athey, 1987; Cabral and Mata, 2003). 


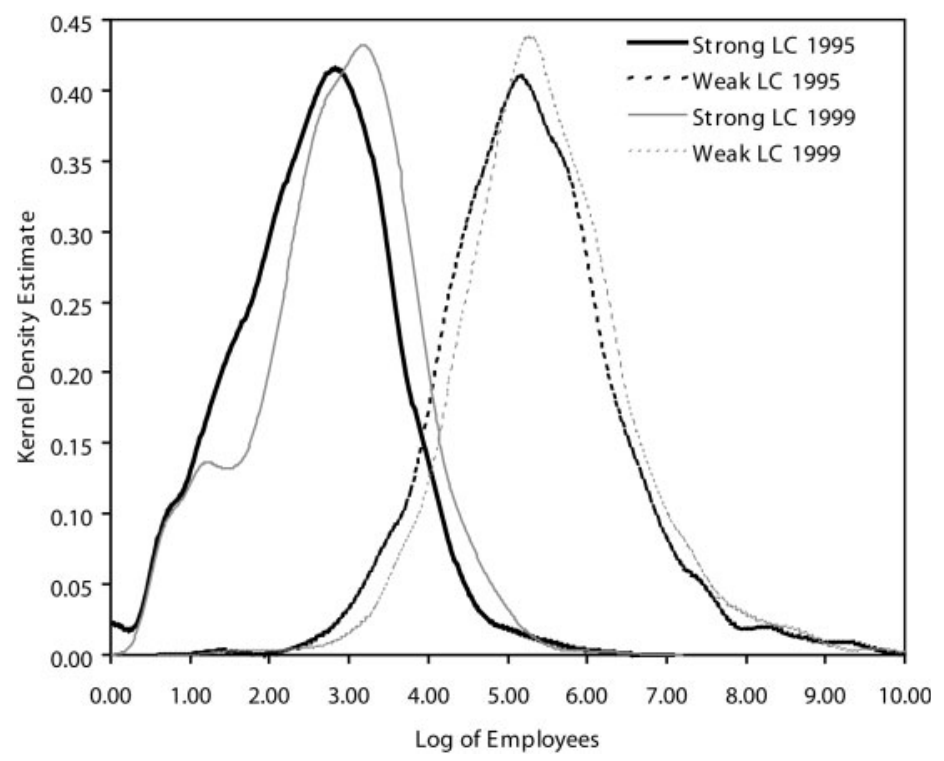

Figure 13 Non-parametric kernel density estimation of log of employees year distributions conditional on cash flow (CF)/sales. Strong liquidity constraints (LC) means CF/sales in the first decile. Weak LC means CF/sales in the tenth decile. Kernel density estimates are performed employing a normal kernel and a 0.2 bandwidth.

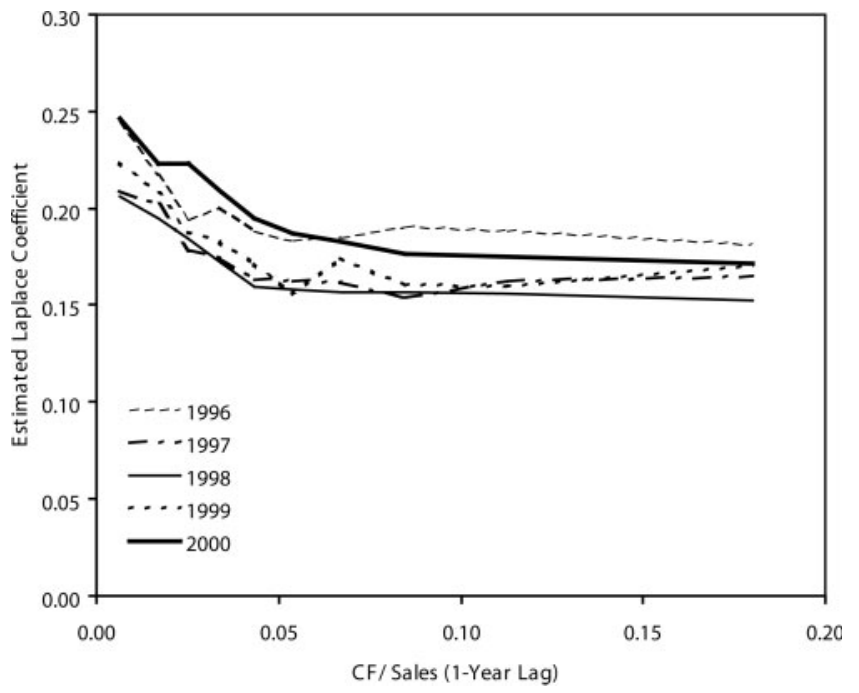

Figure 14 Estimated Laplace coefficients for Laplace fit of Employees growth rates distributions conditional on cash flow $(\mathrm{CF}) /$ sales. 


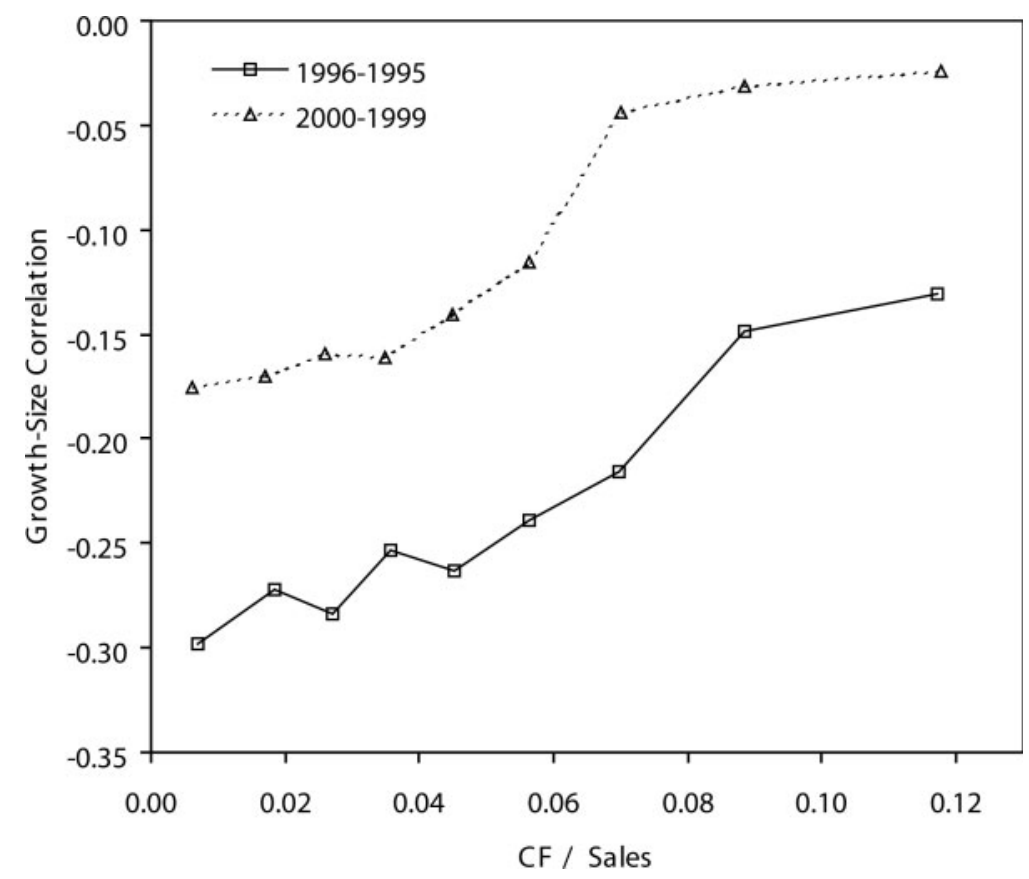

Figure 15 Correlation between employees growth rate at time $t$ and size distributions at time $t-1$, conditional on $\mathrm{CF} /$ sales at time $t-1$. Bins computed as 10 percentiles.

Furthermore, cash flow ratios, size, and growth rates are more variable among younger firms than among older ones. ${ }^{33}$

Suppose now to simultaneously control for age and liquidity constraints. More specifically, let us define "young" (respectively "old") those firms which belong to the first (respectively tenth) decile of the log AGE distribution in $1995 .{ }^{34}$ Accordingly, let us call "SLC" and, respectively, "WLC" firms which belong to the first and, respectively, tenth decile of the SCF distribution in 1995. Consider now the sub-sample of "young" and SLC firms (YSLC) — and, accordingly, the sub-sample of "old" and WLC firms (OWLC) - and let us study size and growth distributions of YSLC and OWLC firms over time.

As Figure 17 shows, YSLC firms grew persistently more not only than OWLC ones but also than firms which were just "young" in 1995. Furthermore, YSLC firms which were "small" in 1995 (i.e., which belonged, in addition, to the first decile of the 1995

\footnotetext{
${ }^{33}$ More precisely, binned average (respectively standard deviation) of log of employees and log of scaled cash flow are increasing (respectively decreasing) with respect to (within-bins) averages of log of age. Conversely, binned growth-rates average and standard deviation are both decreasing with (within-bins) averages of log of age.

${ }^{34}$ Incidentally, "young" firms have less than 12 years while "old" ones have more than 42 years.
} 


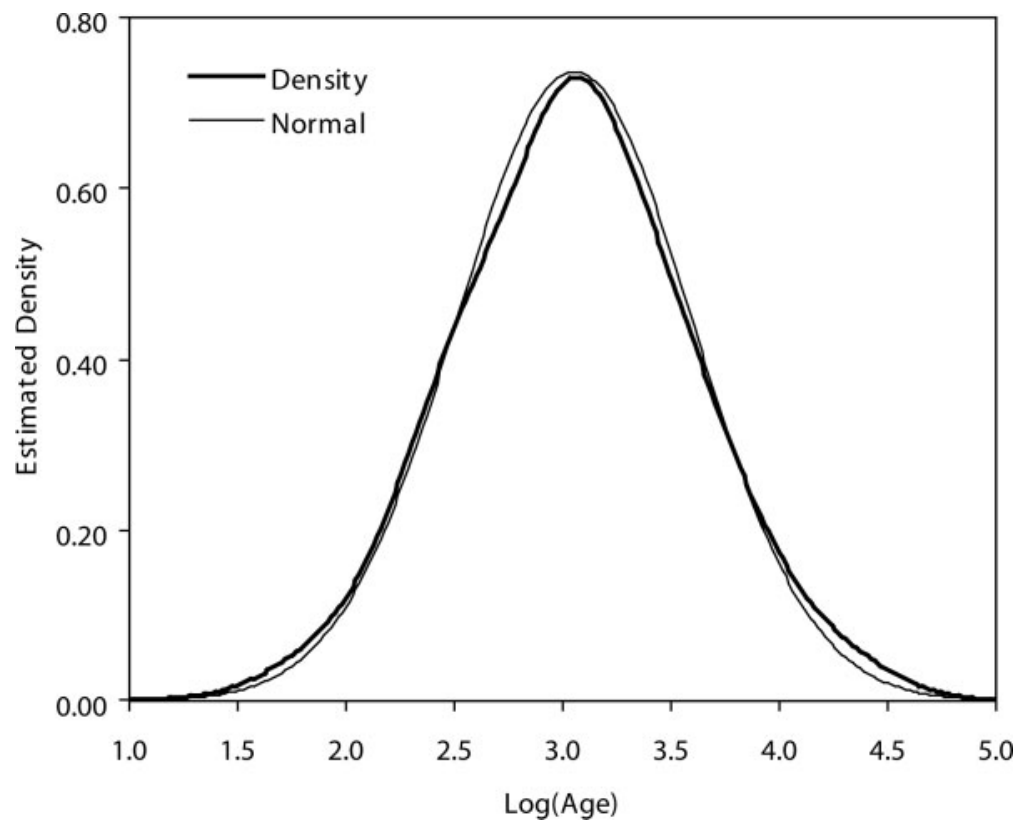

Figure 16 Non-parametric kernel density estimation of log of age distribution. Normal fit shown as dotted line. Kernel density estimates is performed employing a normal kernel and a 0.2 bandwidth.
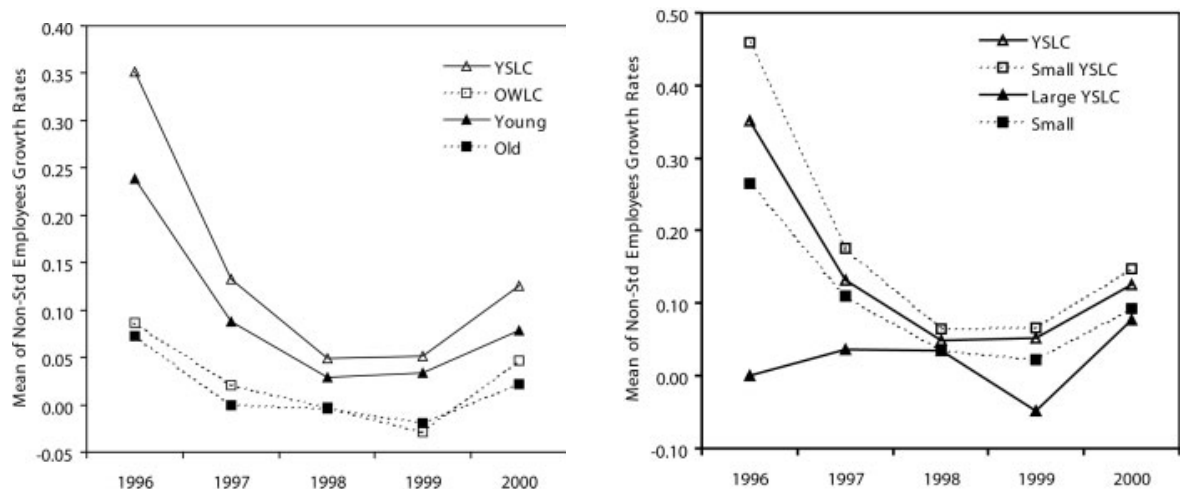

Figure 17 Average of growth rates distributions conditioned on age, cash flow (CF)/sales, and size in 1995. YSLC, young firms with small CF/sales (first decile); OWLC, old firms with large CF/sales (tenth decile); small (large) firms, firms within the first (tenth) decile of 1995 employees distribution.

employees distribution) experienced from 1996 to 2000 better-than-average growth rates and out performed YSLC firms which were "large" in 1995 (i.e., which also belonged to the tenth decile of the 1995 employees distribution). This means that, by focusing on young, cash-constrained (and possibly small) firms, we are eliciting a 

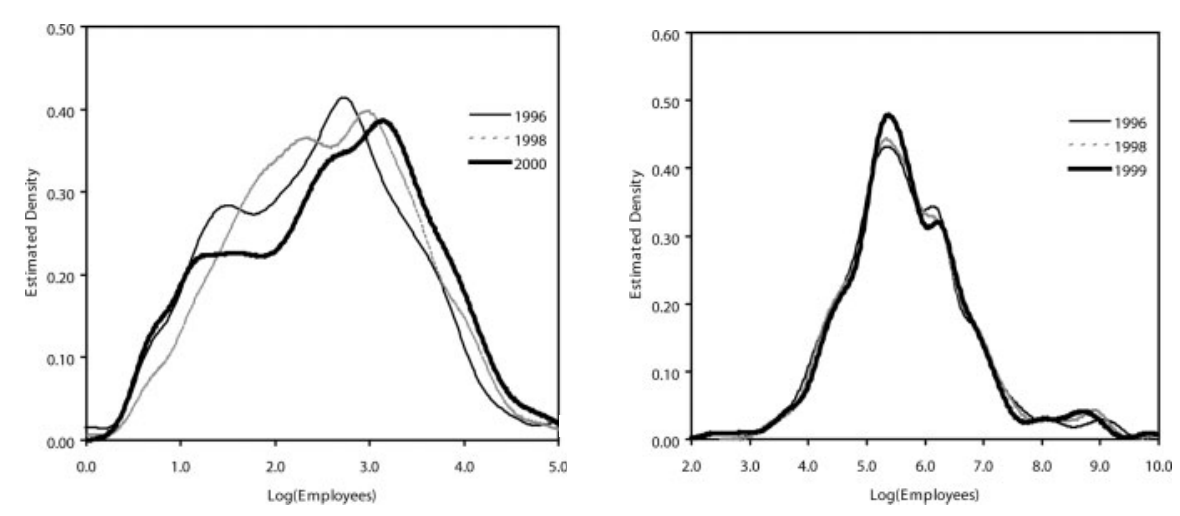

Figure 18 Non-parametric kernel density estimation of log of employees distributions over time. Left, YSLC firms; Right, OWLC firms; YSLC, young firms (first decile) with small CF/ sales (first decile). OWLC, old firms (tenth decile) with large CF/sales (tenth decile). Normal kernel. Bandwith, 0.2

sub-sample of dynamic firms which, despite (or even thanks to) low levels of cash flow ratios, are able to enjoy high growth rates in the subsequent periods. ${ }^{35}$

These pieces of evidence indicate that some weak catching-up process has been occurring during 1995-2000 (Figure 18). Indeed, YSLC firm size distributions shift to the right while OWLC ones are almost unchanged.

Shifts in size distributions from 1995 to 2000 are, however, better detectable if one controls for age only (as the number of observations increases). Figure 19 shows that the distribution of "old" firms in 1995 was to the right of "young" ones (and slightly more concentrated). Between 1995 and 2000, "young" firms grew more than "old" ones: size distributions in 2000 are closer than in 1995 (Figures 20 and 21). To the contrary, "old" firms enjoyed very weak growth, as their 1995 and 2000 size distributions almost coincide (Figure 22). Similar results can be obtained by exploring how cash flow distributions change over time for "young" and "old" firms.

Finally, log of size distributions all depart from normality but we do not find any statistically detectable change in their shape. Contrary to Cabral and Mata (2003), who report (for Portuguese firms) evidence about shifts toward less skewed size distributions over time, Italian ones (conditional on age and/or cash flow) are always well approximated by highly skewed densities across the entire period of observation.

\footnotetext{
${ }^{35}$ Since we are only observing surviving firms, further analyses are required to take care of any selection effects present in our data.
} 


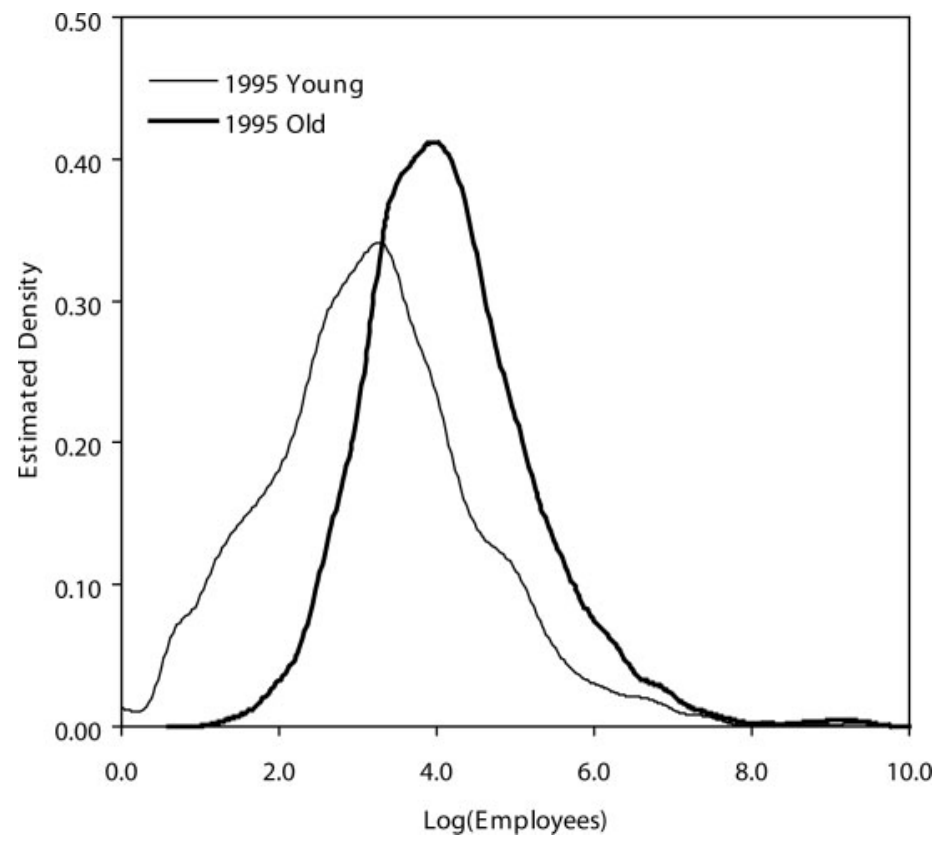

Figure 19 Non-parametric kernel density estimation of log of employees distribution. Young firms versus old firms in 1995. Young firms, firms in the first decile. Old firms, firms in the tenth decile. Normal kernel. Bandwith, 0.2

\section{Conclusions}

In this article, we have analyzed the relationships between liquidity constraints and firm growth dynamics for Italian manufacturing firms. Our main goal was to assess whether any detectable departure from the LPE might be better explained by taking into account the link between financial factors and growth.

Moreover, in light of the recent theoretical work by Cooley and Quadrini (2001) on age-growth dynamics conditional on firm size, we have empirically investigated the relationship between size, age, and growth, when the presence of financial market frictions is directly taken into account.

Gibrat type regression exercises on pooled data have shown that liquidity constraints (as proxied by cash flow scaled by firm sales) engender a negative, statistically significant, effect on growth once one controls for sheer size. Moreover, smaller firms grow more, even when one controls for liquidity constraints.

A negative age effect on growth is significantly detectable in our regression exercises when we do not control for firm financial constraints. LRTs suggest indeed that age (linear and quadratic) effects on growth, conditional on size, becomes irrelevant 


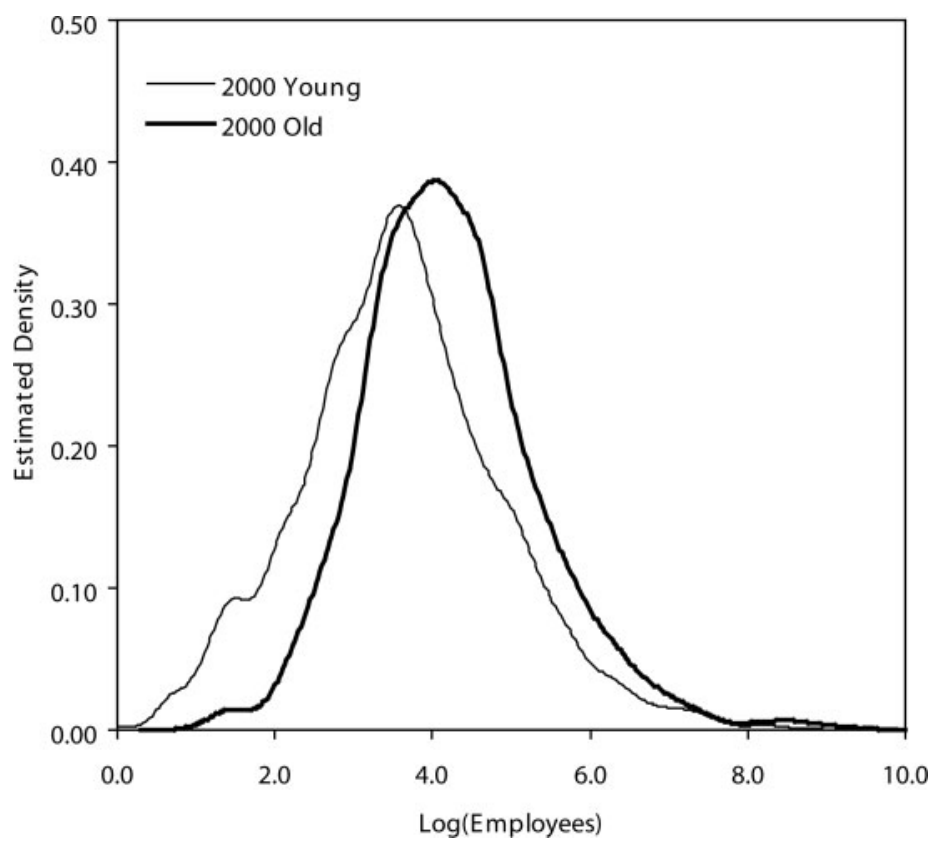

Figure 20 Non-parametric kernel density estimation of log of employees distribution. Young firms versus old firms in 2000. Young firms, firms in the first decile; old firms, firms in the tenth decile. Normal kernel. Bandwith, 0.2

when we directly incorporate liquidity constraints in the equation. This represents an interesting empirical test to the results in Cooley and Quadrini (2001), which show that selection mechanisms and firms technological heterogeneity are not able by themselves to explain the negative dependance of growth rates on age once one control for firm size while this can be explained once one accounts for financial frictions in the model.

The evidence against the LPE is further reinforced by a statistical analysis of pooled distributions. We find that size distributions depart from log-normality while growth rates are well approximated by fat-tailed, tent-shaped (Laplace) densities. Moreover, firms facing stronger liquidity constraints grow less and experience more volatile growth patterns. The negative impact of size on growth seems to increase in magnitude as liquidity constraints become more severe. Growth rate distributions seem, however, to be quite robust to cash flow ratios, once one controls for mean-variance shifts.

We also studied the evolution of size, growth, and scaled cash flow distributions over time. Our exercises suggest that the magnitude of the size-growth correlation has substantially decreased through time for any level of cash flow. Moreover, the negative impact of liquidity constraints on firm growth — which we found to be quite strong in our pooled sample-becomes more ambiguous when one disaggregates across years. 


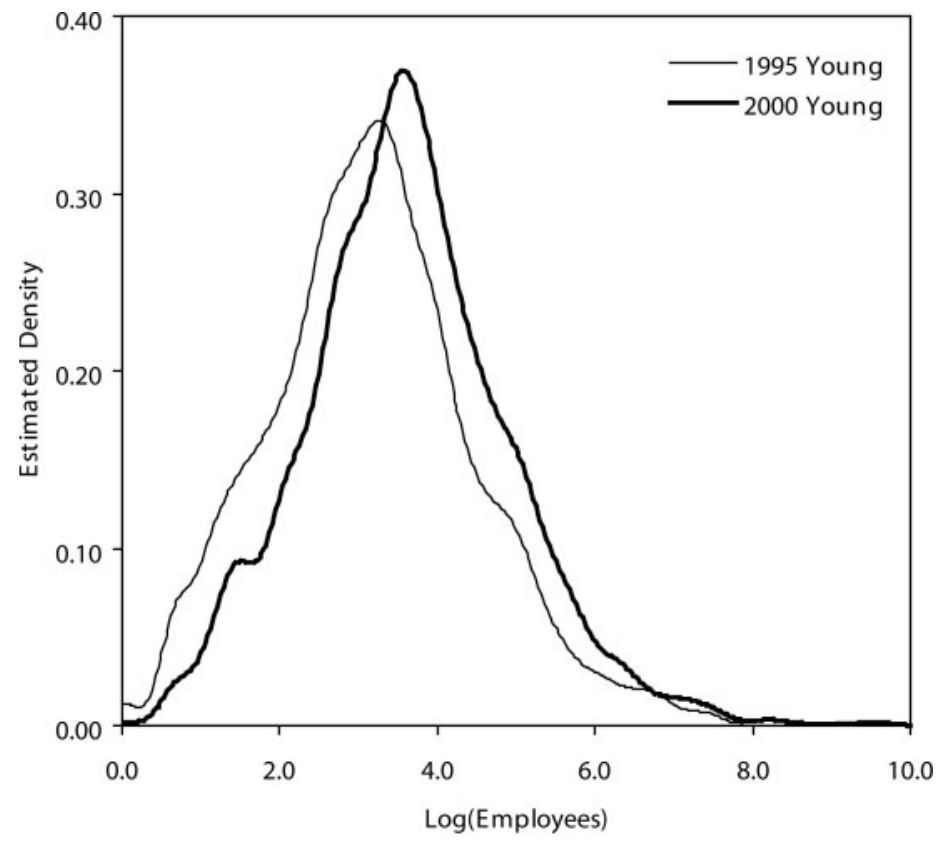

Figure 21 Non-parametric kernel density estimation of log of employees distribution. Young firms in 1995 and 2000. Young firms, firms in the first decile; old firms, firms in the tenth decile. Normal kernel. Bandwith, 0.2

We also find that firms which were young and SLC at the beginning of the sample period grew persistently more than those which were just young and than those which were old and WLC. Those firms turn out to be typically small and quite dynamic entities, which are capable of experiencing high performances despite they were highly cash-constrained at the beginning of the sample period.

Finally, shifts to the right in size distributions for young and SLC firms can also be detected. However, in contrast to existing literature (Cabral and Mata, 2003), size distributions remain quite skewed in the entire period.

\section{Acknowledgements}

Thanks to Giorgio Amisano, Fabio Arcangeli, Giulio Bottazzi, Piero Cavaleri, Giovanni Dosi, Marco Giarratana, Letizia Giorgetti, Angelo Secchi, and the participants of the 3rd ETE Meeting (Sophia-Antipolis, France, January 2004); the 2004 International Industrial Organization Conference (Chicago, U.S.A., April 2004); and the 2004 International Schumpeter Society Conference (Milan, Italy, June 2004). The comments by two anonymous referees have been very useful in shaping this version of 


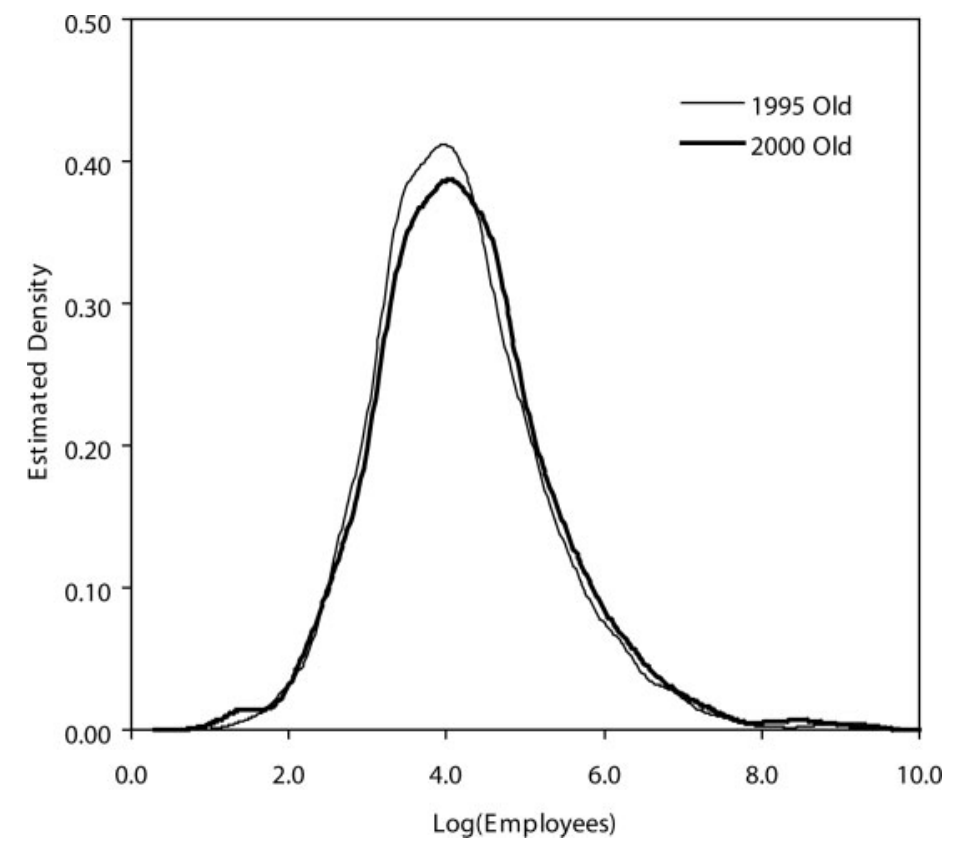

Figure 22 Non-parametric kernel density estimation of log of employees distribution. Old firms in 1995 and 2000. Young firms, firms in the first decile; old firms, firms in the tenth decile. Normal kernel. Bandwith, 0.2

the paper. Alessandra Luzzi acknowledges the "Centre Cournot pour la recherche en économie" for financial support. All usual disclaimers apply.

\section{Addresses for correspondence}

Giorgio Fagiolo, Department of Economics, University of Verona, Verona, Italy and Laboratory of Economics and Management, Sant' Anna School of Advanced Studies, Pisa, Italy. e-mail: giorgio.fagiolo@sssup.it

Alessandra Luzzi, Department of Business Administration, Universidad Carlos III, Madrid, Spain and Laboratory of Economics and Management, Sant' Anna School of Advanced Studies, Pisa, Italy. e-mail: alessandra.luzzi@uc3m.es

\section{References}

Albuquerque, R. and H. Hopenhayn (2004), 'Optimal lending contracts and firm dynamics,' Review of Economic Studies, 71, 85-315. 
Amaral, L., S. Buldryev, S. Havlin, H. Leschhorn, F. Maas, M. Salinger, H. Stanley and M. Stanley (1997), 'Scaling behavior in economics: I. empirical results for company growth,' Journal de Physique I France, 7, 621-633.

Audretsch, D. and J. Elston (2002), 'Does firm size matter? Evidence on the impact of liquidity constraints on firm investment behaviour in Germany,' International Journal of Industrial Organization, 20, 1-17.

Barron, D., E. West and M. Hannan (1994), 'A time to growth and a time to die: growth and mortality of credit unions in New York City, 1914-1990,' The American Journal of Sociology, $100,381-421$.

Becchetti, L. and G. Trovato (2002), 'The determinations of growth for small and medium sized firms. The role of the availability of external finance,' Small Business Economics, 19, 291-306.

Bond, S. and C. Meghir (1994), 'Dynamic investment models and the firms financial policy,' Review of Economic Studies, 61, 197-222.

Bond, S., J. Elston, J. Mairesse and B. Mulkay (2003), 'Financial factors and the investment in Belgium, France, Germany, and the United Kingdom: a comparison using company panel data,' The Review of Economics and Statistics, 85, 153-165.

Bottazzi, G. and A. Secchi (2003a), 'Why are distributions of firm growth rates tent-shaped?' Economic Letters, 80, 415-420.

Bottazzi, G. and A. Secchi (2003b), 'Common properties and sectoral specificities in the dynamics of U.S. manufacturing firms,' Review of Industrial Organization, 23, 217-232.

Bottazzi, G., G. Dosi, M. Lippi, F. Pammolli and M. Riccaboni (2001), 'Innovation and corporate growth in the evolution of the drug industry,' International Journal of Industrial Organization, 19, 1161-1187.

Bottazzi, G., E. Cefis and G. Dosi (2002), 'Corporate growth and industrial structures: some evidence from the Italian manufacturing industry,' Industrial and Corporate Change, 11, 705-723.

Cabral, L. (1995), 'Sunk costs, firm size and firm growth,' Journal of Industrial Economics, 43, $161-172$.

Cabral, L. and J. Mata (2003), 'On the evolution of the firm size distribution: facts and theory,' American Economic Review, 93, 1075-1090.

Carpenter, R. and B. Petersen (2002), 'Is the growth of small firms constrained by internal finance?' Review of Economics and Statistics, 84, 298-309.

Carroll, G. and M. Hannan (1999), The Demography of Corporations and Industries. Princeton University Press: Princeton, NJ.

Cooley, T. and V. Quadrini (2001), 'Financial markets and firm dynamics,' American Economic Review, 91, 1286-1310.

Devereaux, M. and F. Schiantarelli (1989), 'Investment, financial factors, and cash flow: evidence from UK panel data,' Working Paper 3116, NBER.

Elston, J. (2002), 'An examination of the relationship between firm size, growth and liquidity in the Neuer Markt,' Discussion Paper 15/02, Economic Research Centre of the Deutsche Bundesbank. 
Evans, D. (1987), 'Tests of alternative theories of firm growth,' Journal of Political Economy, 95, 657-674.

Fazzari, S. and M. Athey (1987), 'Asymmetric information, financing constraints, and investments,' Review of Economics and Statistics, 69, 481-487.

Fazzari, S., R. Hubbard and B. Petersen (1988a), 'Financing constraints and corporate investment,' Brookings Papers on Economic Activity, 1, 141-195.

Fazzari, S., R. Hubbard and B. Petersen (1988b), 'Investment, financing decisions, and tax policy,' American Economic Review, 78, 200-205.

Fazzari, S., R. Hubbard and B. Petersen (1996), 'Financing constraints and corporate investment: response to Kaplan and Zingales,' Working Paper 5462, NBER.

Galeotti, M., F. Schiantarelli and F. Jaramillo (1994), 'Investment decisions and the role of debt, liquid assets and cash flow: evidence from Italian panel data,' Applied Financial Economics, 4, 121-132.

Geroski, P. (2000), 'The growth of firms in theory and practice,' in Foss, N. and V. Mahnke (eds.), Competence, Governance, and Entrepreneurship. Oxford University Press: Oxford, pp. 168-186.

Gibrat, R. (1931), Les Inégalités Economiques. Librairie du Recueil Sirey: Paris.

Gilchrist, S. and C. Himmelberg (1995), 'Evidence on the role of cash flow for investment,' Journal of Monetary Economics, 36, 541-572.

Goyal, V., K. Lehn and S. Racic (2002), 'Growth opportunities and corporate debt policy: the case of the U.S. Defense Industry,' Journal of Financial Economics, 64, 35-59.

Hall, B. (1987), 'The relationship between firm size and firm growth in the U.S. manufacturing sector,' Journal of Industrial Economics, 35, 583-606.

Hall, B. (1992), 'Investment and research and development at the firm level: does the source of financing matter?' Working Paper 4096, NBER.

Harhoff, D., K. Stahl and M. Woywode (1998), 'Legal form, growth and exit of West-German firms: empirical results from manufacturing, construction, trade and service industries,' Journal of Industrial Organization, 46, 453-488.

Hart, P. and S. Prais (1956), 'The analysis of business concentration: a statistical approach,' Journal of the Royal Statistical Society, 119A, 150-191.

Holtz-Eakin, D., D. Joulfaian and S. Harvey (1994), 'Sticking it out: entrepreneurial survival and liquidity constraints,' Journal of Political Economy, 102, 53-75.

Hopenhayn, H. A. (1992), 'Entry, exit, and firm dynamics in long run equilibrium,' Econometrica, 60, 1127-1150.

Hoshi, T., A. Kayshap and D. Scharfstein (1991), 'Corporate structure, liquidity, and investment: evidence from Japanese industrial groups,' Quarterly Journal of Economics, 106, 33-60.

$\mathrm{Hu}, \mathrm{X}$. and F. Schiantarelli (1997), 'Investment and capital market imperfections: a switching regression approach using U.S. firm panel data,' Review of Economics and Statistics, 80, 466-479.

Hubbard, R. (1998), 'Capital-market imperfections and investment,' Journal of Economic Literature, 36, 193-225. 
Ijiri, Y. and H. Simon (1977), Skew Distributions and the Sizes of Business Firms. North-Holland: New York.

Jorgenson, D. (1971), 'Econometric studies of investment behaviour: a survey,' Journal of Economic Literature, 9, 1111-1147.

Jovanovic, B. (1982), 'Selection and the evolution of industry,' Econometrica, 50, 649-670.

Kalecki, M. (1945), 'On the Gibrat distribution,' Econometrica, 13, 161-170.

Kaplan, S. and L. Zingales (1997), 'Do investment-cashflow sensitivities provide useful measures of financing constraints?' Quarterly Journal of Economics, 112, 169-215.

Lang, L., E. Ofek and R. Stulz (1996), 'Leverage, investment, and firm growth,' Journal of Financial Economics, 40, 3-30.

Lotti, F., E. Santarelli and M. Vivarelli (2003), 'Does Gibrat's law hold among young, small firms?' Journal of Evolutionary Economics, 13, 213-235.

Mairesse, J., B. Hall and B. Mulkay (1999), 'Firm-level investment in France and the United States: an exploration of what we have learned in twenty years,' Annales d 'Economie et de Statistique, 55/56, 27-67.

Mansfield, E. (1962), 'Entry, Gibrat's law, innovation, and the growth of firms,' American Economic Review, 52, 1023-1051.

Mitzenmacher, M. (2002), 'A brief history of generative models for power law and lognormal distributions,' Unpublished Manuscript.

Schiantarelli, F. (1996), 'Financial constraints and investment: a critical survey,' Oxford Review of Economic Policy, 12, 70-89.

Simon, H. and C. Bonini (1958), 'The size distribution of business firms,' American Economic Review, 58, 607-617.

Stanley, M., L. Amaral, S. Buldryev, S. Havlin, H. Leschhorn, F. Maas, M. Salinger and H. Stanley (1996), 'Scaling behavior in the growth of companies,' Nature, 379, 804-806.

Steindl, J. (1965), Random Processes and the Growth of Firms. Griffin: London.

Stiglitz, J. and A. Weiss (1981), 'Credit rationing in markets with imperfect information,' American Economic Review, 71, 393-410.

Sutton, J. (1997), 'Gibrat's Legacy,' Journal of Economic Literature, 35, 40-59.

Sutton, J. (1998), Technology and Market Structure: Theory and History. MIT Press: Cambridge. 